\title{
NOTA
}

\section{Aplicación del método Delphi para determinar los criterios más relevantes de la Responsabilidad Social Empresarial en cada stakeholder ${ }^{1}$}

\section{Marta Camprodon Rosanas, José Sols Lucia, Albert Florensa Giménez y Francesc Martori Adrian²}

Palabras clave: Responsabilidad Social Corporativa (RSC), Responsabilidad Social de la Empresa (RSE), stakeholders, agencias de evaluación de la RSC, método Delphi.

Key Words: Corporate Social Responsibility (CSR) Social Responsibility of Company (SRC), stakeholders, agencies for evaluating CSR, Delphi method.

Mots clés: Responsabilité Sociale Corporative (RSC), Responsabilité Sociale de l'Entreprise, «stakeholders», agences d'évaluation de la RSE; méthode Delphi.

\footnotetext{
' La investigación para la realización de este estudio ha sido subvencionada por Ethos Ramon Llull (Universidad Ramon Llull), con la colaboración de la Generalitat de Catalunya, y ha comportado numerosas entrevistas realizadas a expertos en RSC. Esta tarea fue llevada a cabo por Marta Camprodon durante los meses de junio a diciembre del 2009. Esta fuente propia no será citada cada vez que se utilice. Queremos agradecer la colaboración de todas las empresas que han participado en esta investigación. Las empresas son las siguientes: Alcampo, Badalona Serveis Assistencials, Bon Preu, Coca Cola España, DKV, Esteve, Ferrocarils de la Generalitat de Catalunya, Iberdrola, KhLloreda, La Fageda, MRW, Nestlé y Timberland.

${ }^{2}$ Los cuatro autores son investigadores en la Facultad de Economía IQS (Instituto Químico de Sarrià, Universidad Ramon Llull, Barcelona), miembros de la Cátedra de Ética y Pensamiento Cristiano del IQS, así como del Laboratorio de Análisis y Crítica Social (LACS) del mismo centro.
} 


\section{Introducción}

En los artículos "Las agencias de evaluación de la Responsabilidad Social Cor-

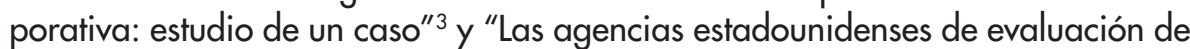
la Responsabilidad Social Empresarial" ${ }^{4}$, publicados en esta revista, se analizan las agencias de evaluación europeas y norteamericanas de la Responsabilidad Social Corporativa (RSC). En esos artículos se señalaban dos razones por las cuales había cristalizado la preocupación por la RSC en algunos sectores de la sociedad. Por una parte, en los años 80 del siglo pasado, se acentuó en Estados Unidos la preocupación por conocer el destino del dinero que se depositaba en los bancos, incrementándose así el número de inversores que deseaban compatibilizar un buen resultado financiero con un adecuado impacto social y medioambiental (aunque, como ya es sabido, la preocupación por buscar una coherencia entre la inversión y los ideales propios había nacido dos siglos antes, en el siglo XVIII, también en los Estados Unidos, en el seno de la comunidad de los cuáqueros) $)^{5}$. Por otra parte, a medida que se incrementaba el número de clientes e inversores que indagaban sobre la responsabilidad social de las empresas, el número de empresas preocupadas por su responsabilidad social también aumentaba.

Las agencias de evaluación de la RSC analizan el grado de responsabilidad social de las empresas $y$, normalmente, las comparan con el sector al que pertenece la empresa en cuestión. Estas agencias pueden ofrecer tres servicios: 1 / la evaluación declarativa (en la cual el estudio es encargado por un inversor socialmente responsable interesado en saber cómo se comporta una empresa en particular), 2/ la evaluación solicitada (en la cual el estudio es encargado por la propia empresa para conocer sus puntos fuertes y sus puntos a mejorar en cuanto a la RSC se refiere), y $3 /$ los índices de responsabilidad social (que son índices bursátiles creados a partir de la empresas mejor evaluadas, procedentes del análisis de la evaluación declarativa). El problema más importante que presentan muchas de las agencias de evaluación de la RSC es su opacidad respecto a la metodología que utilizan al analizar el grado de responsabilidad social de una empresa. El desconocimiento de los métodos de evaluación de las agencias hace imposible conocer cuáles son los criterios de evaluación a la hora de juzgar la responsabilidad social que se le exige a una empresa para

${ }^{3}$ Cfr. M. CAMPROdOn - J. SOLS - A. FloRensa (2006).

${ }^{4}$ Cfr. M. CAMPRODON - J. SOLS - A. Florensa (2009).

${ }^{5}$ Cfr. F. DÉJEAN (2005, p. 21-23). 
considerarla socialmente responsable. Es esta problemática la que ha impulsado esta investigación. El objetivo de la investigación ha sido buscar un conjunto de criterios validados por un grupo expertos a través del método Delphi, como importante herramienta para implementar o evaluar la política de RSC de una empresa. La determinación y la jerarquización de esos criterios también pueden servir para elaborar un documento de partida que sirva de guía a las empresas que deseen poner en marcha políticas de RSC o revisar las que practican. Para llevar a cabo esta investigación nos hemos puesto en contacto con empresas de distinto tamaño y de diferentes sectores económicos, ya que se pretendía determinar y jerarquizar unos criterios con validez universal, con independencia del tamaño y del sector de la empresa. Más adelante, puede resultar interesante ampliar la investigación en dos direcciones: 1/ realizar el mismo estudio en otra área geográfica y compararlo con los resultados obtenidos en España para constatar si la RSC tiene elementos característicos según en el territorio dónde estén instaladas las empresas; y 2 / tal como apuntábamos más arriba, estudiar los criterios concretos que debe considerar una empresa de un sector determinado para desarrollar una buena práctica de la RSC.

\section{La metodología de la investigación}

En esta investigación hemos utilizado el método Delphi'. El método Delphi aparece a finales de los años 40 en el centro de investigación de The Rand Corporation, en Estados Unidos. Dalkey y Helmer ${ }^{7}$ definen el método Delphi como una técnica de investigación que tiene como objeto obtener el consenso de una opinión grupal fidedigna a partir de un grupo de expertos.

\section{I. Características del método Delphi}

Los requisitos fundamentales del método Delphi, para Landeta $^{8}$, son los siguientes:

\footnotetext{
${ }^{6}$ Cfr. J. Landeta (1999); Y. Bejar (2009); J. Landeta - J. Matey - V. Ruiz (2003).

7 Cfr. N. Dalkey - O. Helmer (1963, p. 458).

8 Cfr. J. LANDEtA (1999, p. 42-44).
} 
1. Proceso iterativo: los expertos deben ser consultados como mínimo dos veces sobre la misma cuestión. Esta forma de proceder posibilita al experto reconsiderar su postura debido a la información que reciben de las opiniones del resto de los expertos.

2. Anonimato de los participantes: ningún miembro del grupo puede saber quiénes son los demás expertos componentes del panel, ni tampoco conocer las respuestas particulares que corresponden a cada uno de los participantes.

3. Feedback controlado: el intercambio de información entre los expertos se realiza a través del grupo coordinador del estudio, el cual garantiza la utilización de un lenguaje común y elimina toda información que no sea relevante para la investigación.

4. Respuesta estadística del grupo: la entrevista está realizada de forma que pueda hacerse un tratamiento cuantitativo y estadístico de las respuestas. Generalmente la respuesta del grupo viene caracterizada por la mediana de las respuestas individuales de los expertos, y el rango intercuartílico de las estimaciones será el indicador del nivel de consenso.

\subsection{Proceso de la investigación}

La investigación, siguiendo el método Delphi, se inicia definiendo el equipo coordinador, que elabora el cuestionario a utilizar en la consulta a los expertos. En un segundo momento, se contacta, de forma individual, con cada uno de los posibles expertos que participarán en la investigación y se configura el panel de expertos con aquellos que hayan dado su conformidad a participar en la investigación. Se les hace llegar a cada uno de los miembros del panel de expertos la encuesta, para ser contestada. El equipo coordinador recopila las respuestas de todos los expertos para proceder a su análisis estadístico y elabora un segundo cuestionario para cada panelista, en el que cada uno de ellos pueda leer sus propias respuestas comparadas con las respuestas agregadas de los demás. Finalmente los expertos responden y devuelven al equipo coordinador el segundo cuestionario para que éste procese las respuestas y redacte los análisis finales. El gráfico 1 resume las fases de una investigación siguiendo la metodología Delphi. 


\section{GRÁFICO I: Proceso de la investigación}

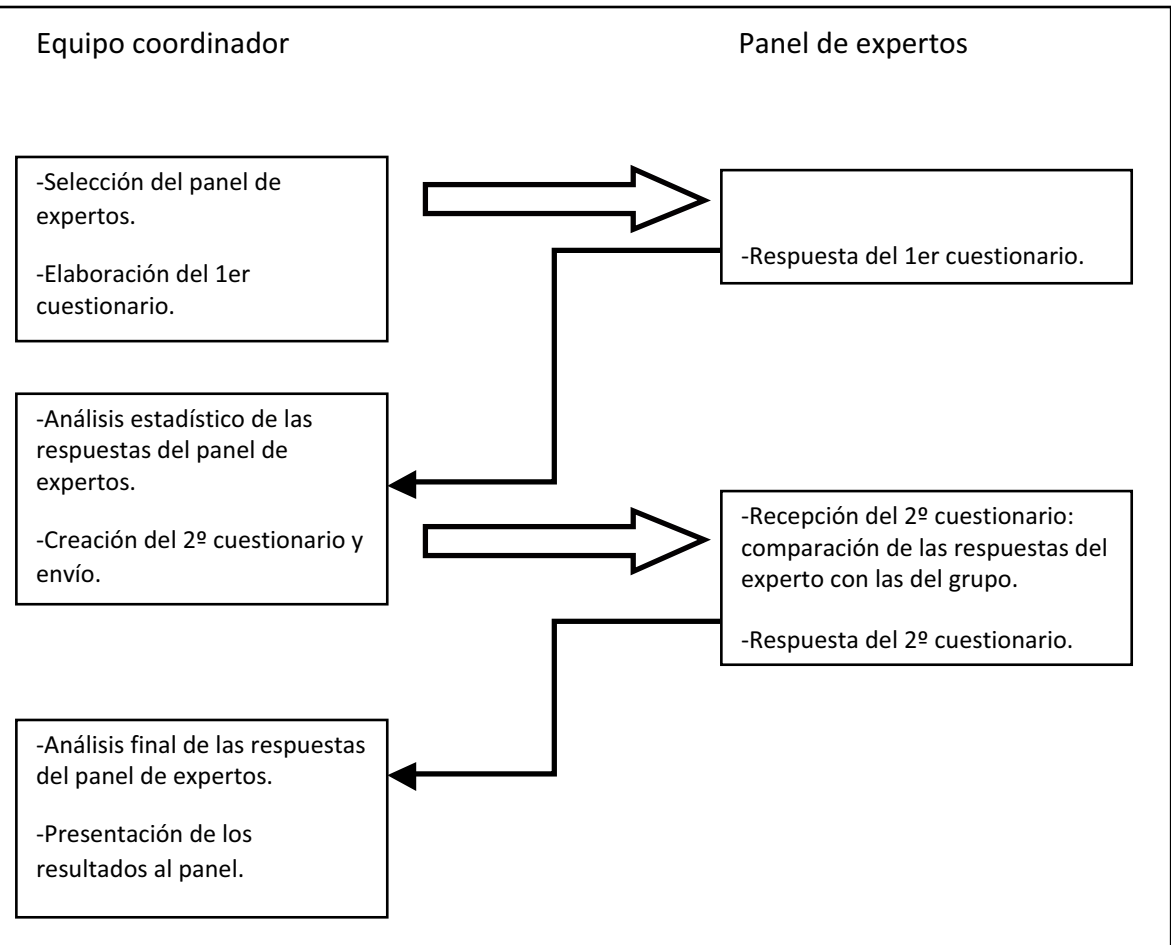

Fuente: propia.

Dado que nuestra investigación pretendía determinar, con la máxima garantía posible cuáles son los criterios más relevantes y universalizables a la hora de evaluar la RSC de una empresa en España, los expertos con los cuáles llevaríamos a cabo la parte nuclear de nuestra investigación debían formar parte de empresas que pudiesen ser consideradas empresas socialmente responsables?. No buscábamos

\footnotetext{
${ }^{9}$ Resulta obvio que tenemos aquí un problema de lógica: ¿̇cómo podemos saber qué empresas son socialmente responsables, si precisamente lo que queremos hacer al entrevistarlas es saber qué criterios haría falta para considerar a una empresa como "socialmente responsable"? Esto es una aporía, por lo que no queda más remedio que cortar el nudo gordiano y empezar a andar: escogemos empresas que, tras haber sido observadas por nosotros y por otros agentes del mercado, se nos presentan como socialmente responsables, y con sus mejores expertos en el tema iniciamos este proceso de delimitación de criterios de evaluación la RSC. En algunas de las empresas escogidas, precisamente el hecho de
} 
respuestas teóricas en este estadio de nuestra investigación, sino acordes con la realidad empírica de la empresa, por ello decidimos conectar con este tipo de expertos. Por otra parte, no queríamos ceñirnos a un sector empresarial concreto, sino intentar que los expertos proviniesen de actividades empresariales distintas, ni tampoco queríamos que las empresas tuvieran tamaños parecidos. La característica que debían tener todas las empresas era que fueran socialmente responsables.

Por lo que se refiere al número de expertos, Landeta (1999) afirma que el número mínimo de éstos para una investigación mediante el método Delphi debe estar comprendido entre 7 y 50 . Finalmente, 13 fue el número de expertos que participó en nuestra investigación. Es importante recalcar que no ha habido ninguna empresa que empezara como panelista y se diera de baja a mitad del proceso. Es decir, las 13 empresas se comprometieron a participar en la investigación y han contestado las dos encuestas. En la tabla 1 puede verse el listado de las empresas a las que pertenecían los expertos entrevistados así como el tipo de actividad que llevan a cabo dichas empresas y su implicación en la RSC.

La propuesta de partida que hicimos a los expertos consideró los siguientes stakeholders: clientes o consumidores, proveedores, empleados, sociedad o entorno social o comunidad, medio ambiente, propietarios o accionistas, alta dirección, competencia y administraciones públicas. Los expertos debían validar los stakeholders propuestos y los criterios que se asociaban a cada uno de ellos. En la tabla 2 puede observarse los criterios que se asociaron a cada stakeholder.

Esta primera propuesta de stakeholders y de criterios proviene de diferentes fuentes. En primer lugar, se inspira en los trabajos de Adela Cortina ${ }^{10}$, cuya obra contribuye a diseñar nuestro marco teórico, en particular sus estudios sobre ética aplicada, ética de la empresa y RSC. También nos inspiramos en la Guía de responsabilidad social de la empresa, elaborada por el Centro Europeo de Empresas Innovadoras de Valencia y por la Fundación ETNOR ${ }^{11}$; en la guía para la elaboración de memorias de sostenibilidad elaborada por el GRI'2; en el Libro Verde de la Comisión

haber tenido en el pasado problemas públicamente conocidos con el tema de la RSC (ecología, derechos humanos, etc.), les ha hecho en los últimos años especialmente sensibles a esta temática, por lo que han contratado expertos en RSC de buen nivel, a los cuales nos hemos dirigido para nuestro estudio.

10 Cfr. A. CORTINA $(2007,1994,1986)$

${ }^{11}$ Cfr. CEEI (2004).

${ }^{12} \mathrm{Cfr}$. GRI (2006). 


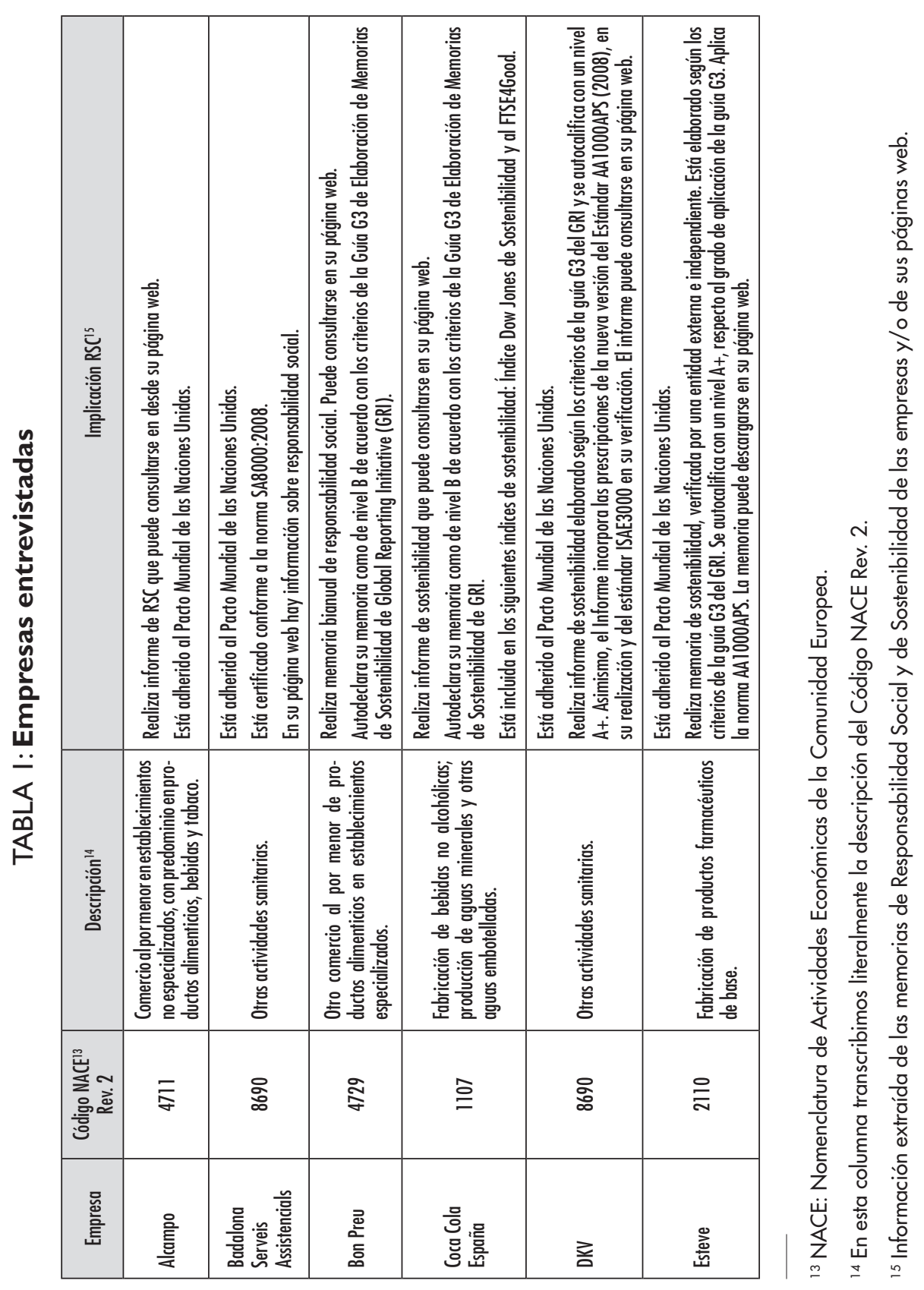

Revista de Fomento Social 65 (2010) 


\begin{tabular}{|c|c|c|c|c|c|c|c|}
\hline 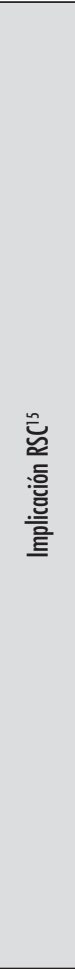 & 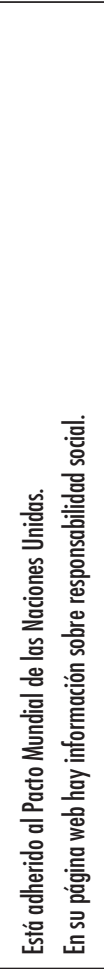 & 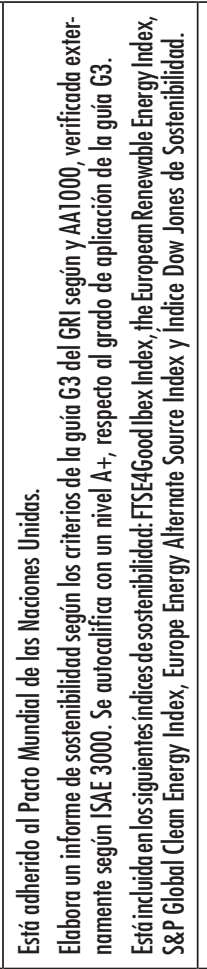 & 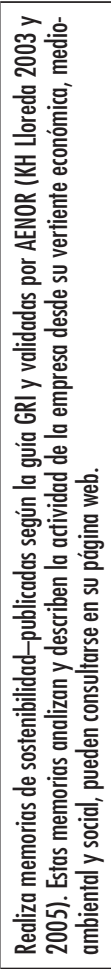 & 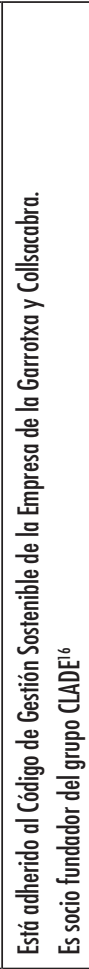 & 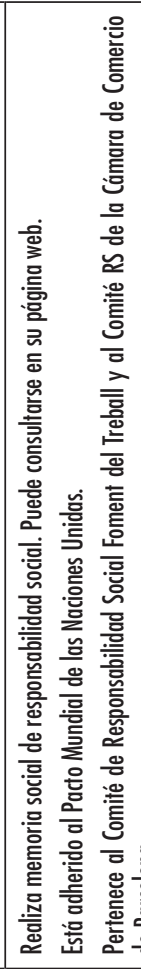 & 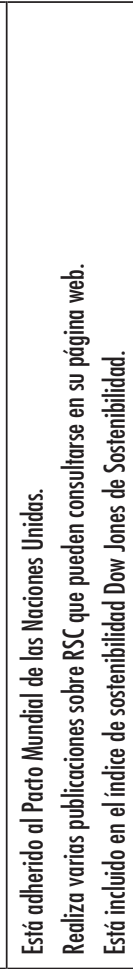 & 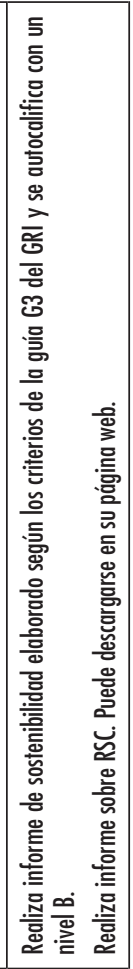 \\
\hline 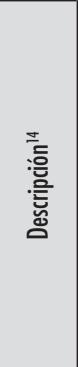 & 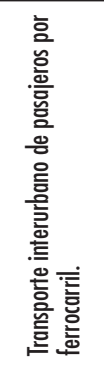 & 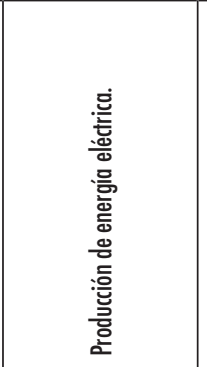 & 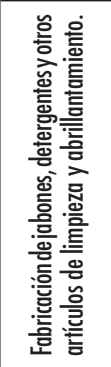 & 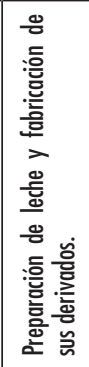 & 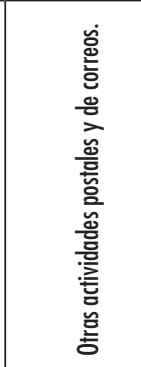 & 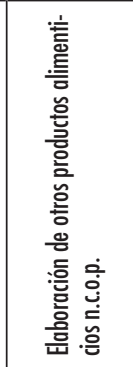 & 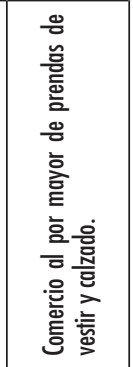 \\
\hline 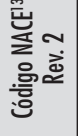 & 产 & $\bar{్}$ & 志 & ్ㅗㅇ & స్ల్గి & $\stackrel{\circ}{\circ}$ & F \\
\hline 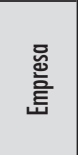 & 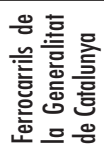 & 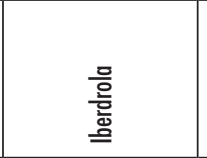 & $\frac{\text { 总 }}{\text { 至 }}$ & $\begin{array}{l}\text { 离 } \\
\text { 离 }\end{array}$ & $\frac{N}{\Sigma}$ & $\stackrel{\infty}{\stackrel{0}{0}}$ & $\begin{array}{l}\text { 亳 } \\
\text { 耪 } \\
\end{array}$ \\
\hline
\end{tabular}

498 
Europea, Fomentar un marco europeo para la responsabilidad social ${ }^{17}$; en el Marco conceptual de la Responsabilidad Social Corporativa de AECA (Asociación Española de Contabilidad y Administración de Empresas) ${ }^{18}$; y, en menor grado, en el cuaderno 2 de Forética ${ }^{19}$ y en la Guía de la Responsabilidad Social Corporativa de la Industria Química propuesta por FEIQUE (Federación Empresarial de la Industria Química Española) ${ }^{20}$.

\section{TABLA 2: Propuesta de criterios}

\begin{tabular}{|l|l|}
\hline Stakeholder & \multicolumn{1}{c|}{ Criterios } \\
\hline & $\begin{array}{l}\text { a) Realizar valoraciones sobre la satisfacción del cliente (por } \\
\text { ejemplo, encuestas). }\end{array}$ \\
& b) Tener un responsable de atención al cliente. \\
& c) Facilitar un contacto en el envasado / producto / servicio \\
por si el cliente / consumidor quisiera hacer una sugerencia o & reclamación.
\end{tabular}

${ }^{17}$ Cfr. Comisión Europea (2001).

${ }^{18}$ Cfr. Comisión de Responsabilidad SOCIAl (2003).

19 Cfr. Fontrodona (2005)

${ }^{20}$ Cfr. FEIQUE (2008). 


\begin{tabular}{|l|l|}
\hline a) Realizar valoraciones sobre la satisfacción del proveedor (por \\
ejemplo, encuestas). \\
b) Las compras realizadas por la empresa consideran criterios \\
sociales. \\
c) Las compras realizadas por la empresa consideran criterios \\
medioambientales. \\
d) La empresa exige el cumplimiento de los derechos humanos a \\
los proveedores. \\
e) La empresa incluye criterios de responsabilidad social en los \\
contratos firmados con sus proveedores que van más allá del \\
simple cumplimiento de los derechos humanos. \\
f) La empresa mantiene relaciones estables con los proveedores.
\end{tabular}




\begin{tabular}{|c|c|}
\hline $\begin{array}{l}\text { Sociedad } \\
\text { / Entorno } \\
\text { Social / } \\
\text { Comunidad }\end{array}$ & $\begin{array}{l}\text { a) La empresa presenta informe de las acciones sociales. } \\
\text { b) La empresa presenta memoria de sostenibilidad. } \\
\text { c) La empresa evalúa las repercusiones de sus actividades. } \\
\text { d) La empresa realiza seguimiento de las repercusiones de sus } \\
\text { actividades. } \\
\text { e) La empresa contrata mano de obra local. } \\
\text { f) La empresa contrata colectivos con dificultades de acceso al } \\
\text { empleo. } \\
\text { g) La empresa colabora con alguna ONG. } \\
\text { h) La empresa lucha contra la exclusión social. } \\
\text { i) La empresa hace mecenazgo cultural }\end{array}$ \\
\hline $\begin{array}{l}\text { Medio } \\
\text { Ambiente }\end{array}$ & $\begin{array}{l}\text { a) La empresa realiza estudios acerca de su impacto } \\
\text { medioambiental. } \\
\text { b) La empresa tiene políticas de prevención de la contaminación } \\
\text { del medio ambiente. } \\
\text { c) La empresa tiene políticas de reciclaje. } \\
\text { d) La empresa posee un plan de riesgos medioambientales. } \\
\text { e) La empresa tiene un programa de economización de } \\
\text { recursos. } \\
\text { f) La empresa tiene un programa de gestión de las emisiones. } \\
\text { g) La empresa tiene un programa de gestión de residuos. }\end{array}$ \\
\hline $\begin{array}{l}\text { Propietarios } \\
\text { / Accionistas }\end{array}$ & $\begin{array}{l}\text { a) Elaboración de informes voluntarios e independientes sobre la } \\
\text { actuación de la empresa en materia financiera. } \\
\text { b) Auditorías periódicas de la gestión de la empresa. } \\
\text { c) Divulgación de las normas de gobierno a los stakeholders de } \\
\text { la empresa. } \\
\text { d) Retribución equitativa entre la propiedad y los trabajadores. }\end{array}$ \\
\hline $\begin{array}{l}\text { Alta } \\
\text { Dirección }\end{array}$ & $\begin{array}{l}\text { a) Definir la misión de la empresa, el código ético y/o los valores } \\
\text { de la empresa. } \\
\text { b) Comunicar a los stakeholders la misión de la empresa, el código } \\
\text { ético y/o los valores de la empresa. } \\
\text { c) Hacer memorias con información sobre los aspectos económicos, } \\
\text { sociales y medioambientales (triple cuenta de resultados). } \\
\text { d) Tener un coordinador de la gestión de la responsabilidad } \\
\text { social. } \\
\text { e) Tener una política anticorrupción. }\end{array}$ \\
\hline
\end{tabular}




\begin{tabular}{|l|l|}
\hline Competencia & $\begin{array}{l}\text { a) Participación de la empresa en foros del sector. } \\
\text { b) No difundir información falseada de los competidores. } \\
\text { c) No utilización de medios ilegales para obtener información de } \\
\text { la competencia. }\end{array}$ \\
\hline $\begin{array}{l}\text { Adminis- } \\
\text { traciones } \\
\text { Públicas }\end{array}$ & $\begin{array}{l}\text { a) La empresa participa en grupos de trabajo y foros de } \\
\text { expertos. }\end{array}$ \\
\hline
\end{tabular}

Con este material se elaboró un cuestionario que se remitió a los expertos. Dicho cuestionario presentaba dos partes. En la primera, los expertos debían considerar la lista de stakeholders que se les había propuesto, ya fuera para validarla o para proponer la supresión o la incorporación de algún stakeholder. En la segunda parte, los expertos debían valorar cada uno de los criterios mediante una escala Likert de 5 niveles (muy de acuerdo / de acuerdo / indiferente / en desacuerdo / muy en desacuerdo), y a continuación debían ordenarlos jerárquicamente. Esta segunda parte tenía dos objetivos: en primer lugar validar los criterios que habíamos propuesto y en segundo lugar jerarquizar los criterios que se habían considerado para cada stakeholder para de esta manera obtener una guía a la hora de orientar una política de responsabilidad social.

Antes de remitir el cuestionario a los expertos, fue sometido a la revisión y a la aprobación de un grupo de profesores de la Facultad de Economía del IQS de la Universidad Ramón Llull que no pertenecían ni al panel de expertos ni al equipo coordinador de la investigación.

Una vez finalizada la primera ronda de entrevistas, se procesó toda la información y se creó un nuevo cuestionario específico para cada experto donde éste podía ver sus respuestas comparadas con las respuestas agregadas del resto de expertos, cuya identidad sólo conocía el equipo coordinador de la investigación. En este cuestionario se le pedía al experto que, si quería, podía modificar su opinión inicial al ver lo que habían contestado los demás miembros del panel de manera agregada. Por lo tanto, un experto nunca ha visto lo que ha contestado otro de forma individual, sino que siempre ha visto sus propias respuestas contrastadas con las del resto del grupo de expertos de forma agregada. 


\section{Resultados de la encuesta}

A continuación presentamos los resultados obtenidos. Se analizan en el mismo orden en el que aparecían en los cuestionarios.

En primer lugar, en la primera ronda de las entrevistas, se preguntó a los expertos si creían que la lista de stakeholders que se les presentaba era correcta. Algunos expertos nos propusieron: 1) que dividiéramos el stakeholder "clientes y consumidores" en dos stakeholders diferentes ( $\mathrm{a} /$ clientes y b/ consumidores) ya que podía darse el caso de que el cliente directo fuera una distribuidora, y que, en definitiva, el consumidor final fuese el usuario del producto; 2) que añadiéramos el stakeholder "ONG", y 3) que añadiéramos el stakeholder "prensa". En la segunda ronda de entrevistas incorporamos las modificaciones propuestas y las expusimos a los expertos. Las respuestas obtenidas fueron las siguientes: 1) el $53,8 \%$ de los expertos estaba de acuerdo en diferenciar el stakeholder "clientes y consumidores" frente al $46,2 \%$, que estaba en contra; 2) el 61,5\% respondió que estaba de acuerdo en incorporar el stakeholder "ONG", mientras que el 38,5\% no lo estaba; y 3 ) el $53,8 \%$ de los expertos estaba de acuerdo en incorporar el stakeholder "prensa", frente al $46,2 \%$, que no lo estaba. De aquí concluimos que el stakeholder "ONG" debería incorporarse a la lista, mientras que se desestima incorporar el stakeholder "prensa", ya que es interior al stakeholder "sociedad". Por lo que se refiere a la iniciativa de dividir en dos el stakeholder "clientes y consumidores", según las opiniones de los expertos, consideramos que no debe llevarse a cabo tal división, dado que sólo en algunas empresas el cliente directo es una distribuidora y el consumidor final el usuario del producto, sin embargo no consideraríamos erróneo que una empresa dividiera en dos el stakeholder "clientes y consumidores" si su cliente directo fuera distinto del consumidor final.

Posteriormente, se presentó a los expertos la lista de los criterios considerados para cada uno de los stakeholders (esta lista puede verse en la tabla 3). Los criterios debían ser valorados según una escala Likert de 5 niveles (muy de acuerdo / de acuerdo / indiferente / en desacuerdo / muy en desacuerdo). Con esta valoración queríamos validar los criterios propuestos. A continuación, se propuso a los expertos que ordenasen jerárquicamente los criterios siendo el número 1 el más importante. Los resultados se mostraran en forma de gráfico Box $-\mathrm{Plot}^{21} \mathrm{y}$, tal como hemos dicho,

${ }^{21}$ El Box-Plot es un gráfico creado por John W. Tukey que representa las distribuciones de un conjunto de datos en cuya construcción se usan las siguientes medidas descriptivas: valor máximo (cola superior del gráfico), valor mínimo (cola inferior del gráfico), primer cuartil, tercer cuartil y mediana (en nuestros gráficos está marcada con una cruz). 
ordenados jerárquicamente según la valoración de los expertos. Los resultados obtenidos muestran que no siempre puede establecerse un orden jerárquico determinante para cada stakeholder, puesto que en algunos casos se dan resultados muy similares para criterios distintos, formándose una jerarquización compuesta por grupos. Es decir, a veces la diferencia entre una posición jerárquica " $x$ " $y$ una " $\mathrm{x}+1$ " puede ser poco relevante, en cuyo caso se consideraría que estos dos criterios conforman un grupo. Normalmente, estos grupos están conformados por criterios que tienen la misma mediana. En la tabla 3 están resumidos los principales parámetros estadísticos analizados en todos los stakeholders. Estos parámetros son la mediana, el máximo, el mínimo, el primer cuartil y el tercer cuartil.

\section{TABLA 3: Resumen de los principales parámetros estadísticos}

\begin{tabular}{|c|l|c|c|c|c|c|}
\hline Stakeholder & \multicolumn{1}{|c|}{ Criterios } & Máximo & $\begin{array}{c}\text { Primer } \\
\text { cuartil }\end{array}$ & Mediana & $\begin{array}{c}\text { Tercer } \\
\text { cuartil }\end{array}$ & Mínimo \\
\hline & $\begin{array}{l}\text { a) Realizar valoraciones sobre la } \\
\text { satisfacción del cliente (por ejem- } \\
\text { plo, encuestas). }\end{array}$ & 7 & 3 & 4 & 6 & 1 \\
\hline $\begin{array}{ll}\text { b) Tener un responsable de aten- } \\
\text { ción al cliente. }\end{array}$ & 8 & 2 & 3 & 5 & 1 \\
\hline $\begin{array}{l}\text { c) Facilitar un contacto en el } \\
\text { envasado / producto / servicio } \\
\text { por si el cliente /consumidor } \\
\text { quisiera hacer una sugerencia o } \\
\text { reclamación. }\end{array}$ & 5 & 2 & 3 & 4 & 2 \\
\hline $\begin{array}{l}\text { Clientes y } \\
\text { consumidores En caso de sugerencia o rec- } \\
\text { lamación, responder siempre al } \\
\text { cliente/consumidor. }\end{array}$ & 6 & 1 & 2 & 3 & 1 \\
\hline $\begin{array}{l}\text { e) La empresa colabora con las } \\
\text { asociaciones de consumidores de } \\
\text { su entorno. }\end{array}$ & 8 & 7 & 7 & 8 & 6 \\
\hline $\begin{array}{l}\text { f) La empresa investiga nuevas } \\
\text { demandas de los clientes. }\end{array}$ & 8 & 5 & 7 & 7 & 1 \\
\hline $\begin{array}{l}\text { g) La empresa tiene previsto algún } \\
\text { protocolo en caso de que tenga } \\
\text { que retirar un lote de productos } \\
\text { del mercado que haya salido } \\
\text { defectuoso. }\end{array}$ & 8 & 4 & 5 & 7 & 1 \\
\hline $\begin{array}{l}\text { h) La empresa hace publicidad } \\
\text { responsable (no engañosa). }\end{array}$ & 8 & 3 & 5 & 6 & 1 \\
\hline
\end{tabular}




\begin{tabular}{|c|l|c|c|c|c|c|}
\hline Stakeholder & \multicolumn{1}{|c|}{ criterios } & Máximo & $\begin{array}{c}\text { Primer } \\
\text { cuartil }\end{array}$ & Mediana & $\begin{array}{c}\text { Tercer } \\
\text { cuartil }\end{array}$ & Mínimo \\
\hline \multirow{5}{*}{ Proveedores } & $\begin{array}{l}\text { a) Realizar valoraciones sobre la } \\
\text { satisfacción del proveedor (por } \\
\text { ejemplo, encuestas). }\end{array}$ & 6 & 6 & 6 & 6 & 5 \\
\hline $\begin{array}{l}\text { b) Las compras realizadas por } \\
\text { la empresa consideran criterios } \\
\text { sociales. }\end{array}$ & 4 & 3 & 4 & 4 & 1 \\
\hline $\begin{array}{l}\text { c) Las compras realizadas por } \\
\text { la empresa consideran criterios } \\
\text { medioambientales. }\end{array}$ & 5 & 2 & 3 & 4 & 2 \\
\hline $\begin{array}{l}\text { d) La empresa exige el cumplim- } \\
\text { iento de los derechos humanos a } \\
\text { los proveedores. }\end{array}$ & 5 & 1 & 1 & 2 & 1 \\
\hline $\begin{array}{l}\text { e) La empresa incluye criterios } \\
\text { de responsabilidad social en los } \\
\text { contratos firmados con sus prove- } \\
\text { dores que van más allá del simple } \\
\text { cumplimiento de los derechos } \\
\text { humanos. }\end{array}$ & 6 & 3 & 3 & 5 & 1 \\
\hline $\begin{array}{l}\text { f) La empresa mantiene relaciones } \\
\text { estables con los proveedores. }\end{array}$ & 6 & 2 & 4 & 5 & 1 \\
\hline $\begin{array}{l}\text { a) Laempresa posee normas escri- } \\
\text { tas contra las prácticas discrimina- } \\
\text { torias entre los empleados. }\end{array}$ & 14 & 2 & 3 & 7 & 1 \\
\hline $\begin{array}{l}\text { b) La empresa vela por la ig- } \\
\text { valdad de oportunidades y no } \\
\text { discriminación. }\end{array}$ & 6 & 1 & 2 & 3 & 1 \\
\hline $\begin{array}{l}\text { c) La empresa comunica a los } \\
\text { empleados la políticadedesarrollo } \\
\text { profesional. }\end{array}$ & 13 & 5 & 8 & 12 & 2 \\
\hline $\begin{array}{l}\text { d) La empresa publica los niveles } \\
\text { salariales. }\end{array}$ & 14 & 8 & 11 & 13 & 3 \\
\hline $\begin{array}{l}\text { e) La Lempresa hace encuestas a los } \\
\text { empleados para conocer el nivel } \\
\text { de satisfacción, el clima laboral } \\
\text { e identificar áreas que requieran } \\
\text { atención. }\end{array}$ & 12 & 4 & 7 & 11 & 1 \\
\hline $\begin{array}{l}\text { f) La empresa tiene un proto- } \\
\text { colo de acogida a los nuevos } \\
\text { trabajadores. }\end{array}$ & 12 & 4 & 9 & 10 & 1 \\
\hline
\end{tabular}




\begin{tabular}{|c|c|c|c|c|c|c|}
\hline Stakeholder & Criterios & Máximo & $\begin{array}{l}\text { Primer } \\
\text { cuartil }\end{array}$ & Mediana & $\begin{array}{l}\text { Tercer } \\
\text { cuartil }\end{array}$ & Mínimo \\
\hline \multirow{8}{*}{ Empleados } & $\begin{array}{l}\text { g) Todos los documentos internos } \\
\text { están escritos en todas las lenguas } \\
\text { donde la empresa tiene oficinas. }\end{array}$ & 14 & 10 & 13 & 14 & 5 \\
\hline & $\begin{array}{l}\text { h) La empresa posibilita la for- } \\
\text { mación de los empleados }\end{array}$ & 8 & 2 & 4 & 5 & 1 \\
\hline & $\begin{array}{l}\text { i) La empresa potencia la } \\
\text { empleabilidad. }\end{array}$ & 14 & 7 & 9 & 10 & 5 \\
\hline & $\begin{array}{l}\text { i) La empresa realiza políticas } \\
\text { activas de conciliación de la vida } \\
\text { familiar y laboral. }\end{array}$ & 9 & 3 & 6 & 7 & 1 \\
\hline & $\begin{array}{l}\text { k) La empresa hace reuniones anu- } \\
\text { ales para informar a los empleados } \\
\text { sobre los resultados. }\end{array}$ & 13 & 7 & 8 & 10 & 4 \\
\hline & $\begin{array}{l}\text { I) La empresa tiene un buzón de } \\
\text { sugerencias. }\end{array}$ & 14 & 7 & 11 & 13 & 4 \\
\hline & $\begin{array}{l}\text { m) La empresa hace partícipes a los } \\
\text { trabajadores de los beneficios. }\end{array}$ & 13 & 5 & 7 & 10 & 3 \\
\hline & $\begin{array}{l}\text { n) La empresa practica el } \\
\text { Kaizen. }\end{array}$ & 14 & 9 & 12 & 14 & 6 \\
\hline \multirow{8}{*}{ Sociedad } & $\begin{array}{l}\text { a) La empresa presenta informe } \\
\text { de las acciones sociales. }\end{array}$ & 9 & 4 & 6 & 7 & 2 \\
\hline & $\begin{array}{l}\text { b) La empresa presenta memoria } \\
\text { de sostenibilidad. }\end{array}$ & 8 & 3 & 3 & 6 & 1 \\
\hline & $\begin{array}{l}\text { c) La empresa evalúa las repercu- } \\
\text { siones de sus actividades. }\end{array}$ & 9 & 2 & 4 & 6 & 1 \\
\hline & $\begin{array}{l}\text { d) La empresa realiza seguimiento } \\
\text { de las repercusiones de sus } \\
\text { actividades. }\end{array}$ & 8 & 2 & 2 & 5 & 1 \\
\hline & $\begin{array}{l}\text { e) La empresa contrata mano de } \\
\text { obra local. }\end{array}$ & 7 & 3 & 5 & 6 & 1 \\
\hline & $\begin{array}{l}\text { f) La empresa contrata colectivos } \\
\text { con dificultades de acceso al } \\
\text { empleo. }\end{array}$ & 6 & 3 & 4 & 4 & 1 \\
\hline & $\begin{array}{l}\text { g) La empresa colabora con alguna } \\
\text { ONG. }\end{array}$ & 9 & 7 & 7 & 8 & 1 \\
\hline & $\begin{array}{l}\text { h) La empresa lucha contra la } \\
\text { exclusión social. }\end{array}$ & 8 & 4 & 5 & 7 & 2 \\
\hline
\end{tabular}




\begin{tabular}{|c|c|c|c|c|c|c|}
\hline Stakeholder & Criterios & Máximo & $\begin{array}{l}\text { Primer } \\
\text { cuartil }\end{array}$ & Mediana & $\begin{array}{l}\text { Tercer } \\
\text { cuartil } \\
\end{array}$ & Mínimo \\
\hline Sociedad & $\begin{array}{l}\text { i) La empresa hace mecenazgo } \\
\text { cultural }\end{array}$ & 9 & 9 & 9 & 9 & 2 \\
\hline \multirow{7}{*}{ Medio Ambiente } & $\begin{array}{l}\text { a) La empresa realiza estu- } \\
\text { dios acerca de su impacto } \\
\text { medioambiental. }\end{array}$ & 7 & 2 & 4 & 6 & 1 \\
\hline & $\begin{array}{l}\text { b) La empresa tiene políticas de } \\
\text { prevención de la contaminación } \\
\text { del medio ambiente. }\end{array}$ & 6 & 1 & 2 & 3 & 1 \\
\hline & $\begin{array}{l}\text { c) La empresa tiene políticas de } \\
\text { reciclaje. }\end{array}$ & 7 & 4 & 5 & 6 & 2 \\
\hline & $\begin{array}{l}\text { d) La empresa posee un plan de } \\
\text { riesgos medioambientales. }\end{array}$ & 7 & 2 & 3 & 6 & 1 \\
\hline & $\begin{array}{l}\text { e) La empresa tiene un programa } \\
\text { de economización de recursos. }\end{array}$ & 7 & 4 & 5 & 7 & 1 \\
\hline & $\begin{array}{l}\text { f) La empresa tiene un programa } \\
\text { de gestión de las emisiones. }\end{array}$ & 7 & 4 & 5 & 6 & 2 \\
\hline & $\begin{array}{l}\text { g) La empresa tiene un programa } \\
\text { de gestión de residuos. }\end{array}$ & 7 & 3 & 3 & 4 & 1 \\
\hline \multirow{4}{*}{ Propietarios } & $\begin{array}{l}\text { a) Elaboración de informes vol- } \\
\text { untarios e independientes sobre } \\
\text { la actuación de la empresa en } \\
\text { materia financiera. }\end{array}$ & 4 & 2 & 2,5 & 3,25 & 1 \\
\hline & $\begin{array}{l}\text { b) Auditorías periódicas de la } \\
\text { gestión de la empresa. }\end{array}$ & 4 & 1 & 1 & 1 & 1 \\
\hline & $\begin{array}{l}\text { c) Divulgación de las normas de } \\
\text { gobierno a los stakeholders de la } \\
\text { empresa. }\end{array}$ & 4 & 2 & 3 & 3,25 & 2 \\
\hline & $\begin{array}{l}\text { d) Retribución equitativa entre la } \\
\text { propiedad y los trabajadores. }\end{array}$ & 4 & 2,75 & 3 & 4 & 1 \\
\hline \multirow[b]{2}{*}{ Alta Dirección } & $\begin{array}{l}\text { a) Definir la misión de la empresa, } \\
\text { el código ético y/o los valores de } \\
\text { la empresa. }\end{array}$ & 3 & 1 & 1 & 1,25 & 1 \\
\hline & $\begin{array}{l}\text { b) Comunicar a los stakehold- } \\
\text { ers la misión de la empresa, el } \\
\text { código ético y/o los valores de } \\
\text { la empresa. }\end{array}$ & 5 & 2 & 3 & 3,25 & 1 \\
\hline
\end{tabular}




\begin{tabular}{|c|c|c|c|c|c|c|}
\hline Stakeholder & Criterios & Máximo & $\begin{array}{l}\text { Primer } \\
\text { cuartil }\end{array}$ & Mediana & $\begin{array}{l}\text { Tercer } \\
\text { cuartil }\end{array}$ & Mínimo \\
\hline \multirow{3}{*}{ Alta Dirección } & $\begin{array}{l}\text { c) Hacer memorias con información } \\
\text { sobre los aspectos económicos, so- } \\
\text { ciales y medioambientales (triple } \\
\text { cuenta de resultados). }\end{array}$ & 5 & 2,75 & 3 & 4 & 1 \\
\hline & $\begin{array}{l}\text { d) Tener un coordinador de la } \\
\text { gestión de la responsabilidad } \\
\text { social. }\end{array}$ & 5 & 2 & 3,5 & 5 & 1 \\
\hline & $\begin{array}{l}\text { e) Tener una política } \\
\text { anticorrupción. }\end{array}$ & 5 & 4 & 4,5 & 5 & 2 \\
\hline \multirow{3}{*}{ Competencia } & $\begin{array}{l}\text { a) Participación de la empresa en } \\
\text { foros del sector. }\end{array}$ & 3 & 3 & 3 & 3 & 1 \\
\hline & $\begin{array}{l}\text { b) No difundir información fal- } \\
\text { seada de los competidores. }\end{array}$ & 3 & 2 & 2 & 2 & 1 \\
\hline & $\begin{array}{l}\text { c) No utilización de mediosilegales } \\
\text { para obtener información de la } \\
\text { competencia. }\end{array}$ & 3 & 1 & 1 & 2 & 1 \\
\hline \multirow{2}{*}{$\begin{array}{l}\text { Administraciones } \\
\text { Públicas }\end{array}$} & $\begin{array}{l}\text { a) La empresa participa en grupos } \\
\text { de trabajo y foros de expertos. }\end{array}$ & 2 & 2 & 2 & 2 & 1 \\
\hline & $\begin{array}{l}\text { b) Colaboración con iniciativas } \\
\text { institucionales. }\end{array}$ & 2 & 1 & 1 & 1 & 1 \\
\hline
\end{tabular}

\section{I. Clientes / Consumidores}

En la tabla 4 pueden observarse las valoraciones que los expertos han hecho de los criterios. Ningún criterio ha sido valorado con un "muy en desacuerdo", y sólo dos, el "e" y el "f", han sido valorados con un "en desacuerdo" en un 8,3\% de las respuestas obtenidas. El criterio " $\mathrm{d}$ " sobresale por encima de todos los demás al obtener una valoración "muy de acuerdo" en el 91,7\% de las respuestas de los expertos. Podemos afirmar que todos los criterios propuestos están validados satisfactoriamente. 
TABLA 4: Resultados de la valoración de los criterios. En \%

\begin{tabular}{|l|c|c|c|c|c|}
\hline \multicolumn{1}{|c|}{ Criterios } & $\begin{array}{c}\text { Muy de } \\
\text { acuerdo }\end{array}$ & $\begin{array}{c}\text { De } \\
\text { acuerdo }\end{array}$ & Indiferente & $\begin{array}{c}\text { En } \\
\text { desacuerdo }\end{array}$ & $\begin{array}{c}\text { Muy en } \\
\text { desacuerdo }\end{array}$ \\
\hline $\begin{array}{l}\text { a) Realizar valoraciones sobre la } \\
\text { satisfacción del cliente (por ejemplo, } \\
\text { encuestas). }\end{array}$ & 58,3 & 33,3 & 8,3 & 0,0 & 0,0 \\
\hline $\begin{array}{l}\text { b) Tener un responsable de atención al } \\
\text { cliente. }\end{array}$ & 66,7 & 33,3 & 0,0 & 0,0 & 0,0 \\
\hline $\begin{array}{l}\text { c) Facilitar un contacto en el envasado } \\
\text { / producto / servicio por si el cliente / } \\
\text { consumidor quisiera hacer una sugeren- } \\
\text { cia o reclamación. }\end{array}$ & 75,0 & 25,0 & 0,0 & 0,0 & 0,0 \\
\hline $\begin{array}{l}\text { d) En caso de sugerencia o recla- } \\
\text { mación, responder siempre al cliente/ } \\
\text { consumidor. }\end{array}$ & 91,7 & 8,3 & 0,0 & 0,0 & 0,0 \\
\hline $\begin{array}{l}\text { e) La empresa colabora con las asocia- } \\
\text { ciones de consumidores de su entorno. }\end{array}$ & 25,0 & 41,7 & 25,0 & 8,3 & 0,0 \\
\hline $\begin{array}{l}\text { f) Laempresa investiga nuevas demandas } \\
\text { de los clientes. }\end{array}$ & 41,7 & 50,0 & 0,0 & 8,3 & 0,0 \\
\hline $\begin{array}{l}\text { g) La empresa tiene previsto algún pro- } \\
\text { tocolo en caso de que tenga que retirar } \\
\text { un lote de productos del mercado que } \\
\text { haya salido defectuoso. }\end{array}$ & 66,7 & 33,3 & 0,0 & 0,0 & 0,0 \\
\hline $\begin{array}{l}\text { h) La empresa hace publicidad respons- } \\
\text { able (no engañosa). }\end{array}$ & 83,3 & 8,3 & 8,3 & 0,0 & 0,0 \\
\hline
\end{tabular}

En el gráfico 1 se presentan los resultados obtenidos de la jerarquización de los criterios. Podemos observar que el criterio " $d$ " es el primero de todos con una

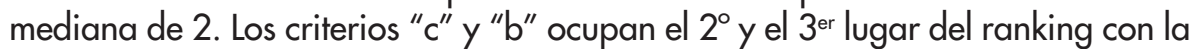
misma mediana, pero las respuestas del " $c$ " son más uniformes que las del " $b$ ", ya que el valor mínimo que ha obtenido este último es el 1, y el valor máximo, el 8. Estos criterios están seguidos por el " $a$ ". A continuación, aparecen " $h$ " $y$ " $g$ ", con una mediana de 5, $y$, finalmente, los criterios que cierran el ranking son " $f$ " $y$ " $e$ ", con una mediana de 7. Resulta interesante observar que, con la jerarquización que han realizado los expertos, se ha confirmado, en parte, la valoración que habían hecho según la escala Likert de 5 niveles, ya que el criterio mejor valorado había sido el "d", y los peor valorados, los "f" $y$ "e". 


\section{GRÁFICO I: Jerarquización de los criterios}

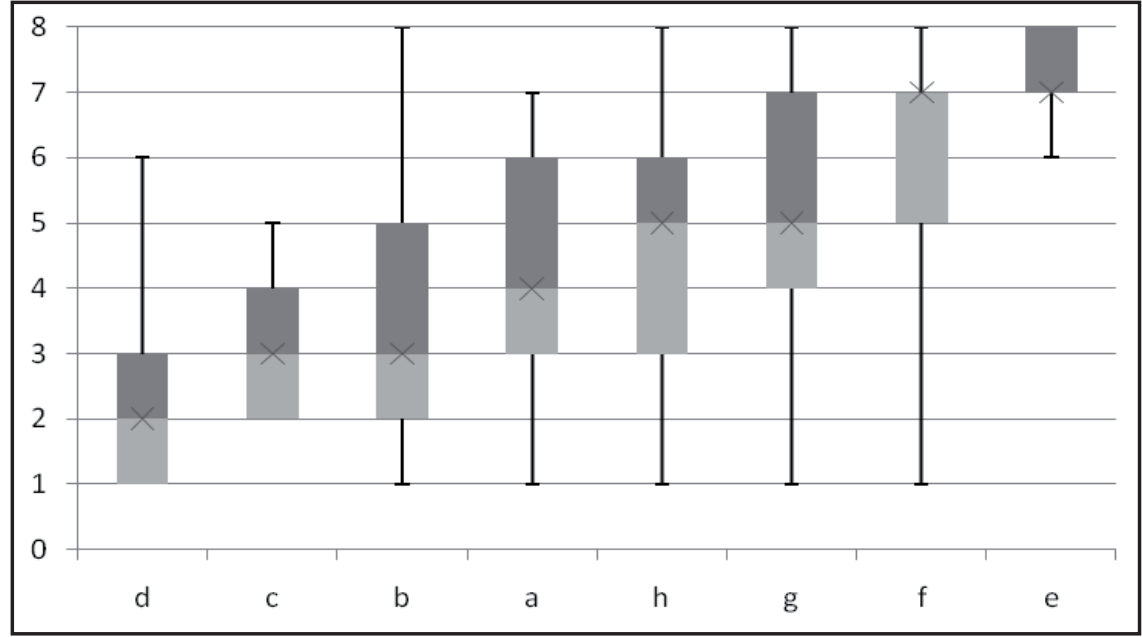

A partir de estos resultados, la jerarquización de los criterios es la siguiente:

1. d) En caso de sugerencia o reclamación, responder siempre al cliente / consumidor.

2. c) Facilitar un contacto en el envasado / producto / servicio por si el cliente / consumidor quisiera hacer una sugerencia o reclamación.

3. b) Tener un responsable de atención al cliente.

4. a) Realizar valoraciones sobre la satisfacción del cliente (por ejemplo, encuestas).

5. h) La empresa hace publicidad responsable (no engañosa).

6. g) La empresa tiene previsto algún protocolo en caso de que tenga que retirar un lote de productos del mercado que haya salido defectuoso.

7. f) La empresa investiga nuevas demandas de los clientes.

8. e) La empresa colabora con las asociaciones de consumidores de su entorno. 


\subsection{Proveedores}

En la tabla 5 puede verse la valoración realizada por los expertos según la escala Likert 5. Puede observarse que el criterio "a" es el peor valorado ya que sólo un $41,74 \%$ está "de acuerdo", y un 16,7\%, "en desacuerdo". El criterio mejor valorado es el " $\mathrm{d}$ ", con un $75 \%$ de los expertos que se manifestaba "muy de acuerdo". Ningún criterio ha sido valorado como "muy en desacuerdo".

TABLA 5: Resultados de la valoración de los criterios. En \%

\begin{tabular}{|l|c|c|c|c|c|}
\hline \multicolumn{1}{|c|}{ Criterios } & $\begin{array}{c}\text { Muy de } \\
\text { acuerdo }\end{array}$ & $\begin{array}{c}\text { De } \\
\text { acuerdo }\end{array}$ & Indiferente & $\begin{array}{c}\text { En } \\
\text { desacuerdo }\end{array}$ & $\begin{array}{c}\text { Muy en } \\
\text { desacuerdo }\end{array}$ \\
\hline $\begin{array}{l}\text { a) Realizar valoraciones sobre la sat- } \\
\text { isfacción del proveedor (por ejemplo, } \\
\text { encuestas). }\end{array}$ & 0,0 & 41,7 & 41,7 & 16,7 & 0,0 \\
\hline $\begin{array}{l}\text { b) Las compras realizadas por la empresa } \\
\text { consideran criterios sociales. }\end{array}$ & 16,7 & 75,0 & 8,3 & 0,0 & 0,0 \\
\hline $\begin{array}{l}\text { c) Las compras realizadas por la empresa } \\
\text { consideran criterios medioambientales. }\end{array}$ & 25,0 & 75,0 & 0,0 & 0,0 & 0,0 \\
\hline $\begin{array}{l}\text { d) Laempresa exige el cumplimiento delos } \\
\text { derechos humanos a los proveedores. }\end{array}$ & 75,0 & 25,0 & 0,0 & 0,0 & 0,0 \\
\hline $\begin{array}{l}\text { e) La empresa incluye criterios de re- } \\
\text { sponsabilidad social en los contratos } \\
\text { firmados con sus proveedores que van } \\
\text { más allá del simple cumplimiento de los } \\
\text { derechos humanos. }\end{array}$ & 16,7 & 75,0 & 8,3 & 0,0 & 0,0 \\
\hline $\begin{array}{l}\text { f) La empresa mantiene relaciones es- } \\
\text { tables con los proveedores. }\end{array}$ & 33,3 & 58,3 & 8,3 & 0,0 & 0,0 \\
\hline
\end{tabular}

En el gráfico 2 presentamos los resultados obtenidos en la segunda serie de entrevistas, donde se presenta la jerarquización de los criterios realizada por los expertos. Como puede observarse, el criterio " $\mathrm{d}$ ", con una mediana de 1, es el mejor valorado mientras que el criterio " $a$ ", con una mediana de 6, es el peor valorado. Los criterios " $b$ " $y$ " $f$ " tienen la misma mediana, pero las opiniones con respecto al criterio "b" son menos dispersas. Esta jerarquización coincide plenamente con las valoraciones según la escala Likert que los expertos habían configurado. 


\section{GRÁFICO 2: Jerarquización de los criterios}

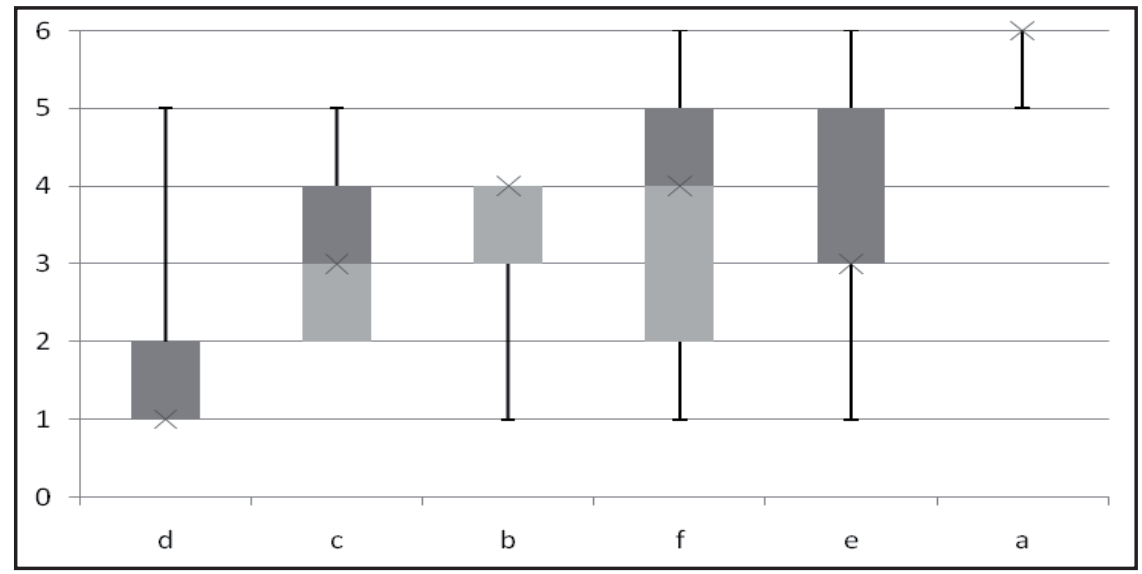

A partir de estos resultados, la jerarquización de los criterios es la siguiente:

1. d) La empresa exige el cumplimiento de los derechos humanos a los proveedores.

2. c) Las compras realizadas por la empresa consideran criterios medioambientales.

3. b) Las compras realizadas por la empresa consideran criterios sociales.

4. f) La empresa mantiene relaciones estables con los proveedores.

5. e) La empresa incluye criterios de responsabilidad social en los contratos firmados con sus proveedores que van más allá del simple cumplimiento de los derechos humanos.

6. a) Realizar valoraciones sobre la satisfacción del proveedor (por ejemplo, encuestas).

\subsection{Empleados}

La valoración realizada por los expertos según la escala Likert 5 puede observarse en la tabla 6. Los criterios peor valorados son " $d$ " $y$ " $g$ ". Por lo contrario, los mejor posicionados son " $b$ ", "f ", " $h$ " $y$ " $k$ ". No hay ningún criterio valorado con "muy en desacuerdo". 
Los expertos ordenaron jerárquicamente estos 14 criterios, y el resultado puede observarse en el gráfico 3 . Analizando el gráfico, se evidencia que se han producido algunos cambios respecto a la valoración realizada por los expertos según la escala Likert 5. Inicialmente los criterios mejor valorados eran " $b$ ", " $f$ ", " $h$ " $y$ " $k$ ", y en la jerarquización de los mismos los criterios " $b$ " $y$ " $h$ " son los más valorados, pero "f y " $k$ ", con una mediana de 9 y 8 , respectivamente, están ahora en las posiciones $5^{a}$ y $8^{a}$. El criterio " $a$ ", situado en $3^{a}$ posición, es el que presenta más dispersión en la respuesta de los expertos, ya que su mediana está en 3, el valor máximo que ha sido valorado, el 14, y el mínimo que ha sido valorado, el 1 . Respecto a los criterios peor valorados, se confirma que en la cola de la jerarquización están " $d$ " $y$ " $g$ ", al igual que la valoración en la escala Likert de 5, aunque se incorpora también el criterio " $\mathrm{n}$ ".

TABLA 6: Resultados de la valoración de los criterios. En \%

\begin{tabular}{|l|c|c|c|c|c|}
\hline \multicolumn{1}{|c|}{ Criterios } & $\begin{array}{c}\text { Muy de } \\
\text { acuerdo }\end{array}$ & $\begin{array}{c}\text { De } \\
\text { acuerdo }\end{array}$ & Indiferente & $\begin{array}{c}\text { En } \\
\text { desacuerdo }\end{array}$ & $\begin{array}{c}\text { Muy en } \\
\text { desacuerdo }\end{array}$ \\
\hline $\begin{array}{l}\text { a) La empresa posee normas escritas } \\
\text { contra las prácticas discriminatorias entre } \\
\text { los empleados. }\end{array}$ & 50,0 & 41,7 & 8,3 & 0,0 & 0,0 \\
\hline $\begin{array}{l}\text { b) La empresa vela por la igualdad de } \\
\text { oportunidades y no discriminación. }\end{array}$ & 58,3 & 41,7 & 0,0 & 0,0 & 0,0 \\
\hline $\begin{array}{l}\text { c) La empresa comunica a los empleados } \\
\text { la política de desarrollo profesional. }\end{array}$ & 16,7 & 75,0 & 8,3 & 0,0 & 0,0 \\
\hline $\begin{array}{l}\text { d) La empresa publica los niveles } \\
\text { salariales. }\end{array}$ & 16,7 & 41,7 & 25,0 & 16,7 & 0,0 \\
\hline $\begin{array}{l}\text { e) La empresa hace encuestas a los } \\
\text { empleados para conocer el nivel de } \\
\text { satisfacción, el clima laboral e identificar } \\
\text { áreas que requieran atención. }\end{array}$ & 25,0 & 58,3 & 16,7 & 0,0 & 0,0 \\
\hline $\begin{array}{l}\text { f) La empresa tiene un protocolo de } \\
\text { acogida a los nuevos trabajadores. }\end{array}$ & 66,7 & 33,3 & 0,0 & 0,0 & 0,0 \\
\hline $\begin{array}{l}\text { g) Todos los documentos internos están } \\
\text { escritos en todas las lenguas donde la } \\
\text { empresa tiene oficinas. }\end{array}$ & 25,0 & 41,7 & 16,7 & 16,7 & 0,0 \\
\hline $\begin{array}{l}\text { h) La empresa posibilita la formación de } \\
\text { los empleados }\end{array}$ & 50,0 & 50,0 & 0,0 & 0,0 & 0,0 \\
\hline
\end{tabular}




\begin{tabular}{|l|c|c|c|c|c|}
\hline \multicolumn{1}{|c|}{ Criterios } & $\begin{array}{c}\text { Muy de } \\
\text { acuerdo }\end{array}$ & $\begin{array}{c}\text { De } \\
\text { acuerdo }\end{array}$ & Indiferente & $\begin{array}{c}\text { En } \\
\text { desacuerdo }\end{array}$ & $\begin{array}{c}\text { Muy en } \\
\text { desacuerdo }\end{array}$ \\
\hline $\begin{array}{l}\text { i) La empresa potencia la } \\
\text { empleabilidad. }\end{array}$ & 16,7 & 75,0 & 8,3 & 0,0 & 0,0 \\
\hline $\begin{array}{l}\text { i) La empresa realiza políticas activas } \\
\text { de conciliación de la vida familiar y } \\
\text { laboral. }\end{array}$ & 41,7 & 58,3 & 0,0 & 0,0 & 0,0 \\
\hline $\begin{array}{l}\text { k) La empresa hace reuniones anuales } \\
\text { para informar a los empleados sobre } \\
\text { los resultados. }\end{array}$ & 50,0 & 50,0 & 0,0 & 0,0 & 0,0 \\
\hline $\begin{array}{l}\text { I) La empresa tiene un buzón de } \\
\text { sugerencias. }\end{array}$ & 33,3 & 50,0 & 16,7 & 0,0 & 0,0 \\
\hline $\begin{array}{l}\text { m) La empresa hace partícipes a los } \\
\text { trabajadores de los beneficios. }\end{array}$ & 33,3 & 58,3 & 8,3 & 0,0 & 0,0 \\
\hline n) La empresa practica el Kaizen. & 8,3 & 75,0 & 16,7 & 0,0 & 0,0 \\
\hline
\end{tabular}

\section{GRÁFICO 3: Jerarquización de los criterios}

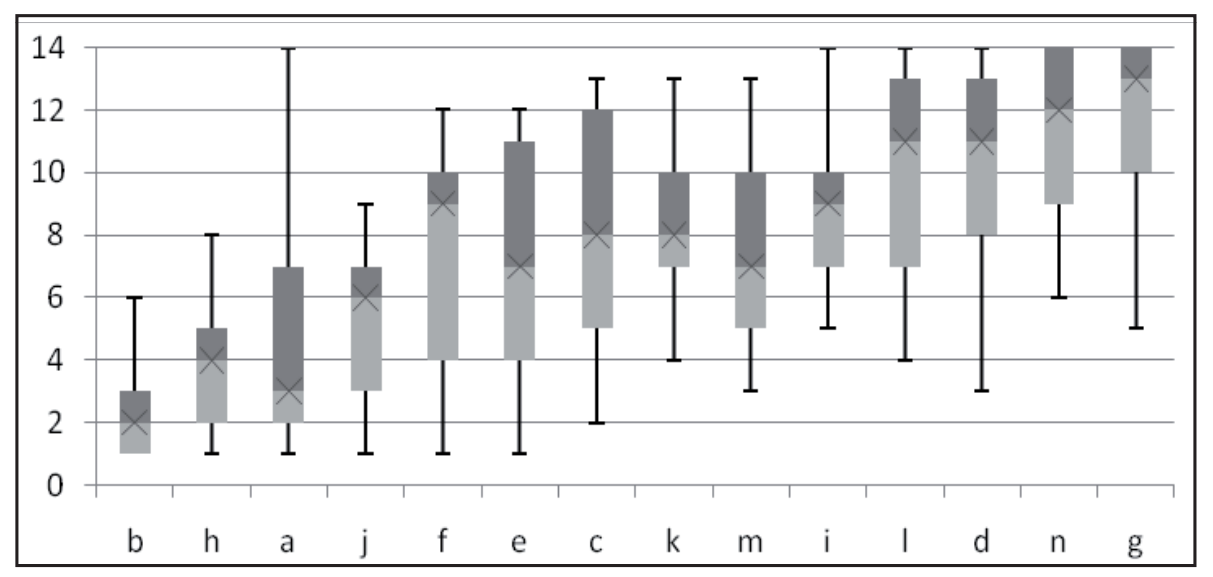

A partir de estos resultados, la jerarquización de los criterios es la siguiente:

1. b) La empresa vela por la igualdad de oportunidades y no discriminación.

2. h) La empresa posibilita la formación de los empleados. 
3. a) La empresa posee normas escritas contra las prácticas discriminatorias entre los empleados.

4. j) La empresa realiza políticas activas de conciliación de la vida familiar y laboral.

5. f) La empresa tiene un protocolo de acogida a los nuevos trabajadores.

6. e) La empresa hace encuestas a los empleados para conocer el nivel de satisfacción, el clima laboral e identificar áreas que requieran atención.

7. c) La empresa comunica a los empleados la política de desarrollo profesional.

8. k) La empresa hace reuniones anuales para informar a los empleados sobre los resultados.

9. m) La empresa hace partícipes a los trabajadores de los beneficios.

10. i) La empresa potencia la empleabilidad.

11. I) La empresa tiene un buzón de sugerencias.

12. d) La empresa publica los niveles salariales.

13. n) La empresa practica el KAIZEN.

14. g) Todos los documentos internos están escritos en todas las lenguas donde la empresa tiene oficinas.

\subsection{Sociedad}

En la tabla 7 presentamos la valoración efectuada por los expertos según la escala Likert 5. Vemos que el 66,7\% afirma estar "muy de acuerdo" con el criterio "b", mientras que el " $g$ " es valorado con un "muy en desacuerdo" por el 8,3\%, y los criterios " $c$ ", " $d$ ", " $h$ " e "i" son valorados con un "en desacuerdo" por el 8,3\%. La valoración de los criterios pertenecientes a este stakeholder tiene menos unanimidad que los anteriormente analizados. 
TABLA 7: Resultados de la valoración de los criterios. En \%

\begin{tabular}{|l|c|c|c|c|c|}
\hline \multicolumn{1}{|c|}{ Criterios } & $\begin{array}{c}\text { Muy de } \\
\text { acuerdo }\end{array}$ & $\begin{array}{c}\text { De } \\
\text { acuerdo }\end{array}$ & Indiferente & $\begin{array}{c}\text { En } \\
\text { desacuerdo }\end{array}$ & $\begin{array}{c}\text { Muy en } \\
\text { desacuerdo }\end{array}$ \\
\hline $\begin{array}{l}\text { a) La empresa presenta informe de las } \\
\text { acciones sociales. }\end{array}$ & 25,0 & 41,7 & 33,3 & 0,0 & 0,0 \\
\hline $\begin{array}{l}\text { b) La empresa presenta memoria de } \\
\text { sostenibilidad. }\end{array}$ & 66,7 & 25,0 & 8,3 & 0,0 & 0,0 \\
\hline $\begin{array}{l}\text { c) La empresa evalúa las repercusiones } \\
\text { de sus actividades. }\end{array}$ & 41,7 & 50,0 & 0,0 & 8,3 & 0,0 \\
\hline $\begin{array}{l}\text { d) La empresa realiza seguimiento de las } \\
\text { repercusiones de sus actividades. }\end{array}$ & 25,0 & 66,7 & 0,0 & 8,3 & 0,0 \\
\hline $\begin{array}{l}\text { e) La empresa contrata mano de obra } \\
\text { local. }\end{array}$ & 16,7 & 66,7 & 16,7 & 0,0 & 0,0 \\
\hline $\begin{array}{l}\text { f) La empresa contrata colectivos con } \\
\text { dificultades de acceso al empleo. }\end{array}$ & 25,0 & 75,0 & 0,0 & 0,0 & 0,0 \\
\hline $\begin{array}{l}\text { g) La empresa colabora con alguna } \\
\text { ONG. }\end{array}$ & 25,0 & 33,3 & 33,3 & 0,0 & 8,3 \\
\hline $\begin{array}{l}\text { h) La empresa lucha contra la exclusión } \\
\text { social. }\end{array}$ & 33,3 & 50,0 & 8,3 & 8,3 & 0,0 \\
\hline i) La empresa hace mecenazgo cultural & 8,3 & 16,7 & 66,7 & 8,3 & 0,0 \\
\hline
\end{tabular}

En el gráfico 4 puede observarse el Box-Plot ordenado jerárquicamente de los 9 criterios analizados. Merece destacarse el resultado de dicha ordenación puesto que pone de manifiesto una disparidad en las opiniones de los expertos que no se ha dado en ninguno de los otros stakeholders. Así, el criterio " $i$ " tiene una mediana de 9, y su posición es la última, ya que casi todos los expertos lo han valorado en dicha posición, pero dos de ellos lo han valorado en las posiciones $2^{a}$ y $4^{a}$. Por este motivo, el gráfico de este criterio resulta tan peculiar. Respecto a las valoraciones Likert, los expertos han considerado que el criterio " $\mathrm{d}$ ", que no resultaba particularmente bien valorado, jerárquicamente debía ser el $1^{\circ}$. Podemos afirmar que las valoraciones realizadas en los criterios pertenecientes al stakeholder "sociedad" no tienen el consenso que aparece en los otros. 


\section{GRÁFICO 4: Jerarquización de los criterios}

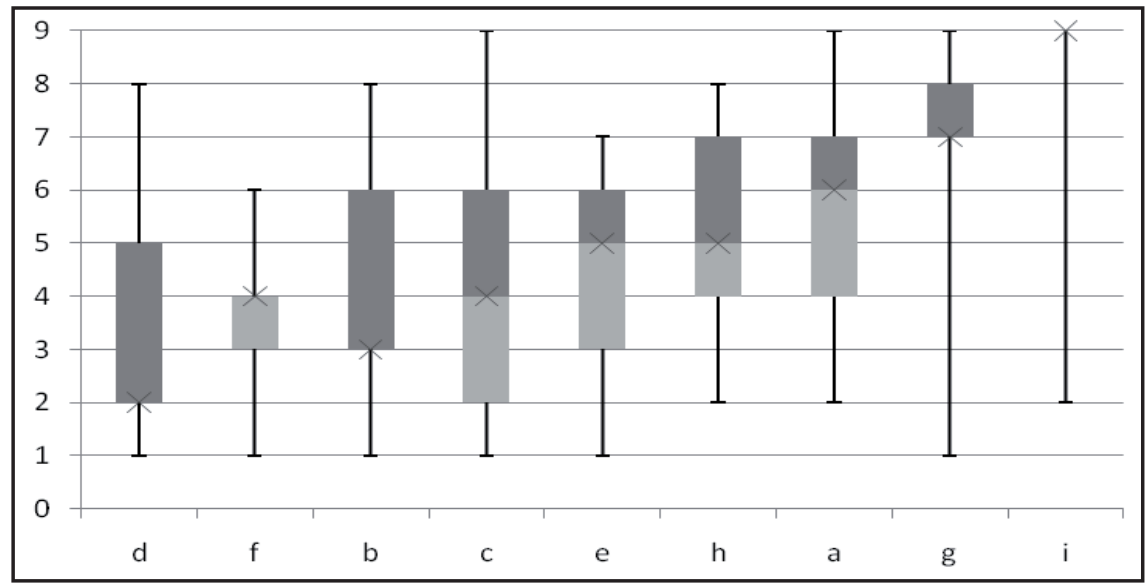

A partir de estos resultados, la jerarquización de los criterios es la siguiente:

1. d) La empresa realiza seguimiento de las repercusiones de sus actividades.

2. f) La empresa contrata colectivos con dificultades de acceso al empleo.

3. b) La empresa presenta memoria de sostenibilidad.

4. c) La empresa evalúa las repercusiones de sus actividades.

5. e) La empresa contrata mano de obra local.

6. h) La empresa lucha contra la exclusión social.

7. a) La empresa presenta informe de las acciones sociales.

8. g) La empresa colabora con alguna ONG.

9. i) La empresa hace mecenazgo cultural. 


\subsection{Medio Ambiente}

En la tabla 8 se presentan las valoraciones que han hecho los expertos según la escala Likert. El 66,7\% está "muy de acuerdo" con el criterio "b", y el 50\%, "muy de acuerdo" con el " $g$ ". No hay ningún criterio con el que algún experto esté "en desacuerdo" o "muy en desacuerdo". Con la evaluación de los expertos, quedan validados los criterios propuestos.

TABLA 8: Resultados de la valoración de los criterios. En \%

\begin{tabular}{|l|c|c|c|c|c|}
\hline \multicolumn{1}{|c|}{ Criterios } & $\begin{array}{c}\text { Muy de } \\
\text { acuerdo }\end{array}$ & $\begin{array}{c}\text { De } \\
\text { acuerdo }\end{array}$ & Indiferente & $\begin{array}{c}\text { En } \\
\text { desacuerdo }\end{array}$ & $\begin{array}{c}\text { Muy en } \\
\text { desacuerdo }\end{array}$ \\
\hline $\begin{array}{l}\text { a) La empresa realiza estudios acerca de } \\
\text { su impacto medioambiental. }\end{array}$ & 41,7 & 50,0 & 8,3 & 0,0 & 0,0 \\
\hline $\begin{array}{l}\text { b) La empresa tiene políticas de pre- } \\
\text { vención de la contaminación del medio } \\
\text { ambiente. }\end{array}$ & 66,7 & 33,3 & 0,0 & 0,0 & 0,0 \\
\hline $\begin{array}{l}\text { c) La empresa tiene políticas de } \\
\text { reciclaje. }\end{array}$ & 41,7 & 58,3 & 0,0 & 0,0 & 0,0 \\
\hline $\begin{array}{l}\text { d) La empresa posee un plan de riesgos } \\
\text { medioambientales. }\end{array}$ & 33,3 & 50,0 & 16,7 & 0,0 & 0,0 \\
\hline $\begin{array}{l}\text { e) La empresa tiene un programa de } \\
\text { economización de recursos. }\end{array}$ & 16,7 & 66,7 & 16,7 & 0,0 & 0,0 \\
\hline $\begin{array}{l}\text { f) La empresa tiene un programa de } \\
\text { gestión de las emisiones. }\end{array}$ & 16,7 & 66,7 & 16,7 & 0,0 & 0,0 \\
\hline $\begin{array}{l}\text { g) La empresa tiene un programa de } \\
\text { gestión de residuos. }\end{array}$ & 50,0 & 50,0 & 0,0 & 0,0 & 0,0 \\
\hline
\end{tabular}

En el gráfico 5 puede observarse el Box-Plot ordenado jerárquicamente de los 7 criterios analizados. Al analizar la gráfica, se confirma que el criterio mejor posicionado es el " $b$ ". Por el contrario, los criterios " $f$ ", " $e$ " $y$ " $c$ " están casi empatados en las posiciones finales con una mediana de 5 . 


\section{GRÁFICO 5: Jerarquización de los criterios}

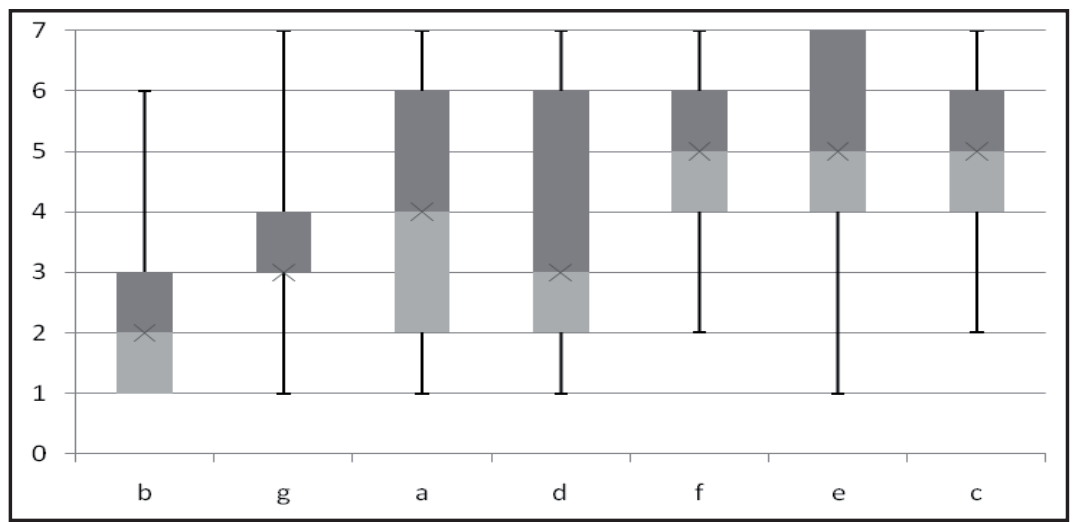

A partir de estos resultados, la jerarquización de los criterios es la siguiente:

1. b) La empresa tiene políticas de prevención de la contaminación del medio ambiente.

2. g) La empresa tiene un programa de gestión de residuos.

3. a) La empresa realiza estudios acerca de su impacto medioambiental.

4. d) La empresa posee un plan de riesgos medioambientales.

5. f) La empresa tiene un programa de gestión de las emisiones.

6. e) La empresa tiene un programa de economización de recursos.

7. c) La empresa tiene políticas de reciclaje.

\subsection{Propietarios}

En la tabla 9 mostramos las valoraciones que hicieron los expertos según la escala Likert. 
TABLA 9: Resultados de la valoración de los criterios. En \%

\begin{tabular}{|l|l|l|l|l|l|}
\hline \multicolumn{1}{|c|}{ Criterios } & $\begin{array}{c}\text { Muy de } \\
\text { acuerdo }\end{array}$ & $\begin{array}{c}\text { De } \\
\text { acuerdo }\end{array}$ & Indiferente & $\begin{array}{c}\text { En } \\
\text { desacuerdo }\end{array}$ & $\begin{array}{c}\text { Muy en } \\
\text { desacuerdo }\end{array}$ \\
\hline $\begin{array}{l}\text { a) Elaboración de informes voluntarios e } \\
\text { independientes sobre la actuación de la } \\
\text { empresa en materia financiera. }\end{array}$ & 27,3 & 63,6 & 9,1 & 0,0 & 0,0 \\
\hline $\begin{array}{l}\text { b) Auditorías periódicas de la gestión } \\
\text { de la empresa. }\end{array}$ & 72,7 & 27,3 & 0,0 & 0,0 & 0,0 \\
\hline $\begin{array}{l}\text { c) Divulgación de las normas de gobierno } \\
\text { a los stakeholders de la empresa. }\end{array}$ & 36,4 & 54,5 & 9,1 & 0,0 & 0,0 \\
\hline $\begin{array}{l}\text { d) Retribución equitativa entre la propie- } \\
\text { dad y los trabajadores. }\end{array}$ & 36,4 & 36,4 & 27,3 & 0,0 & 0,0 \\
\hline
\end{tabular}

El 72,7\% de los expertos están "muy de acuerdo" con el criterio " $b$ " resultando ser el mejor valorado de todos. No hay ningún criterio que destaque por estar mal valorado, por lo que podemos concluir que los criterios están aprobados. En el gráfico 6 puede observarse el Box-Plot ordenado jerárquicamente de los criterios analizados.

\section{GRÁFICO 6: Jerarquización de los criterios}

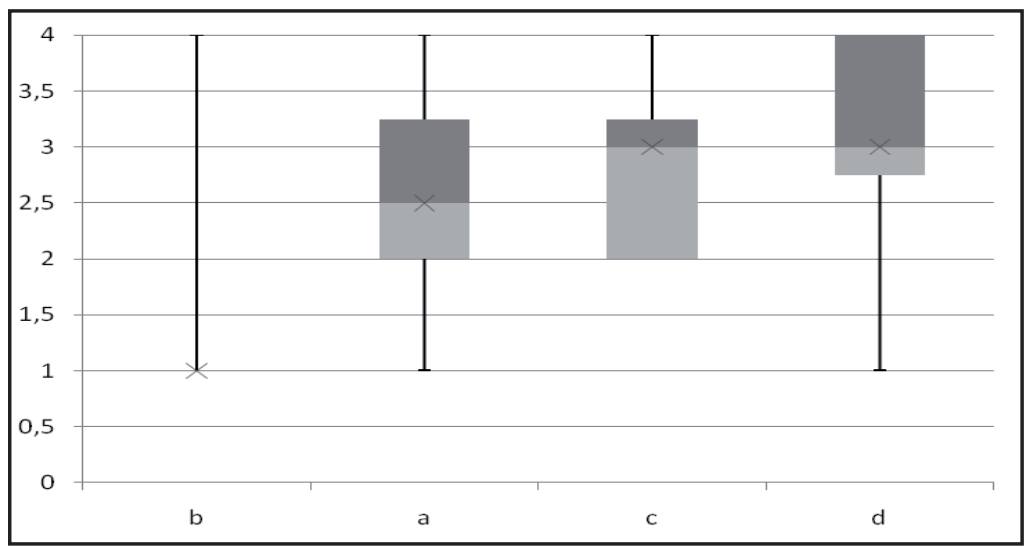

Al observar el Box-Plot, llama la atención el gráfico del criterio "b", pero se entiende su carácter peculiar al saber que, por un lado, la inmensa mayoría de los 
expertos lo ubicó jerárquicamente como el $1^{\circ}$, ya que su mediana es de 1 , y que, por otro, dos expertos lo situaron en el último lugar.

A partir de estos resultados, la jerarquización de los criterios es la siguiente:

1. b) Auditorías periódicas de la gestión de la empresa.

2. a) Elaboración de informes voluntarios e independientes sobre la actuación de la empresa en materia financiera.

3. c) Divulgación de las normas de gobierno a los stakeholders de la empresa.

4. d) Retribución equitativa entre la propiedad y los trabajadores.

\subsection{Alta Dirección}

En la tabla 10 presentamos la valoración efectuada por los expertos según la escala Likert. En la evaluación el criterio "a" resalta con un "muy de acuerdo" en el $72,7 \%$ de las respuestas. El criterio menos favorecido es el "e", con el que el $9,1 \%$ de expertos están "en desacuerdo". No hay ningún criterio valorado como "muy en desacuerdo" por los expertos.

\section{TABLA I0: Resultados de la valoración de los criterios. En \%}

\begin{tabular}{|l|c|c|c|c|c|}
\hline \multicolumn{1}{|c|}{ Criterios } & $\begin{array}{c}\text { Muy de } \\
\text { acuerdo }\end{array}$ & $\begin{array}{c}\text { De } \\
\text { acuerdo }\end{array}$ & Indiferente & $\begin{array}{c}\text { En } \\
\text { desacuerdo }\end{array}$ & $\begin{array}{c}\text { Muy en } \\
\text { desacuerdo }\end{array}$ \\
\hline $\begin{array}{l}\text { a) Definir la misión de la empresa, } \\
\text { el código ético y/o los valores de la } \\
\text { empresa. }\end{array}$ & 72,7 & 27,3 & 0,0 & 0,0 & 0,0 \\
\hline $\begin{array}{l}\text { b) Comunicar a los stakeholders la misión } \\
\text { de la empresa, el código ético y/o los } \\
\text { valores de la empresa. }\end{array}$ & 18,2 & 81,8 & 0,0 & 0,0 & 0,0 \\
\hline $\begin{array}{l}\text { c) Hacer memorias con información } \\
\text { sobre los aspectos económicos, sociales } \\
\text { y medioambientales (triple cuenta de } \\
\text { resultados). }\end{array}$ & 54,5 & 36,4 & 9,1 & 0,0 & 0,0 \\
\hline $\begin{array}{l}\text { d) Tener un coordinador de la gestión de } \\
\text { la responsabilidad social. }\end{array}$ & 54,5 & 27,3 & 18,2 & 0,0 & 0,0 \\
\hline e) Tener una política anticorrupción. & 18,2 & 45,5 & 27,3 & 9,1 & 0,0 \\
\hline
\end{tabular}


En el gráfico 7 presentamos los resultados obtenidos jerárquicamente. Con una mediana de 1 se confirma que el primer criterio del ranking es el " $a$ ". Los criterios " $b$ " y " $c$ " tienen la misma mediana, por lo que su estructuración jerárquica se hace difícil. En cambio, el criterio "e" queda claramente posicionado en el último lugar.

\section{GRÁFICO 7: Jerarquización de los criterios}

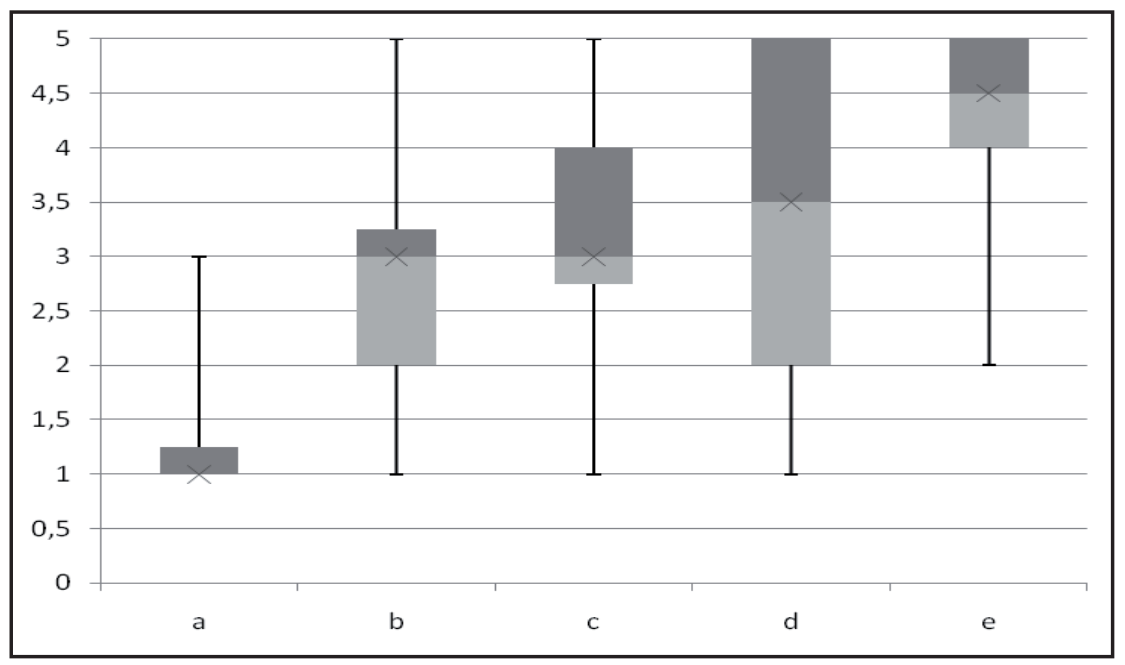

A partir de estos resultados, la jerarquización de los criterios es la siguiente:

1. a) Definir la misión de la empresa, el código ético y/o los valores de la empresa.

2. b) Comunicar a los stakeholders la misión de la empresa, el código ético y/o los valores de la empresa.

3. c) Hacer memorias con información sobre los aspectos económicos, sociales y medioambientales (triple cuenta de resultados).

4. d) Tener un coordinador de la gestión de la responsabilidad social.

5. e) Tener una política anticorrupción. 


\subsection{Competencia}

En la tabla 11, se pueden ver las valoraciones de los criterios que hicieron los expertos según la escala Likert. El mejor valorado es el "c" con el 83,3\% de las opiniones como "muy de acuerdo". Ningún criterio ha sido valorado en "muy en desacuerdo". Quedan validados los criterios propuestos.

En el gráfico 8 puede observarse el Box-Plot ordenado jerárquicamente de los 3 criterios analizados. A pesar de que los máximos y los mínimos de los tres criterios son los mismos, las posiciones jerárquicas son distintas. El criterio " $\mathrm{c}$ ", el $1^{\circ}$, tiene una mediana de 1 , el " $b$ ", el $2^{\circ}$, tiene una mediana de 2 , y el " $a^{\prime}$ ", el $3^{\circ}$, tiene una mediana de 3.

TABLA I I: Resultados de la valoración de los criterios. En \%

\begin{tabular}{|l|c|c|c|c|c|}
\hline \multicolumn{1}{|c|}{ Criterios } & $\begin{array}{c}\text { Muy de } \\
\text { acuerdo }\end{array}$ & $\begin{array}{c}\text { De } \\
\text { acuerdo }\end{array}$ & Indiferente & $\begin{array}{c}\text { En } \\
\text { desacuerdo }\end{array}$ & $\begin{array}{c}\text { Muy en } \\
\text { desacuerdo }\end{array}$ \\
\hline $\begin{array}{l}\text { a) Participación de la empresa en foros } \\
\text { del sector. }\end{array}$ & 33,3 & 58,3 & 8,3 & 0,0 & 0,0 \\
\hline $\begin{array}{l}\text { b) No difundir información falseada de } \\
\text { los competidores. }\end{array}$ & 75,0 & 25,0 & 0,0 & 0,0 & 0,0 \\
\hline $\begin{array}{l}\text { c) No utilización de medios ilegales } \\
\text { para obtener información de la } \\
\text { competencia. }\end{array}$ & 83,3 & 16,7 & 0,0 & 0,0 & 0,0 \\
\hline
\end{tabular}

GRÁFICO 8: Jerarquización de los criterios

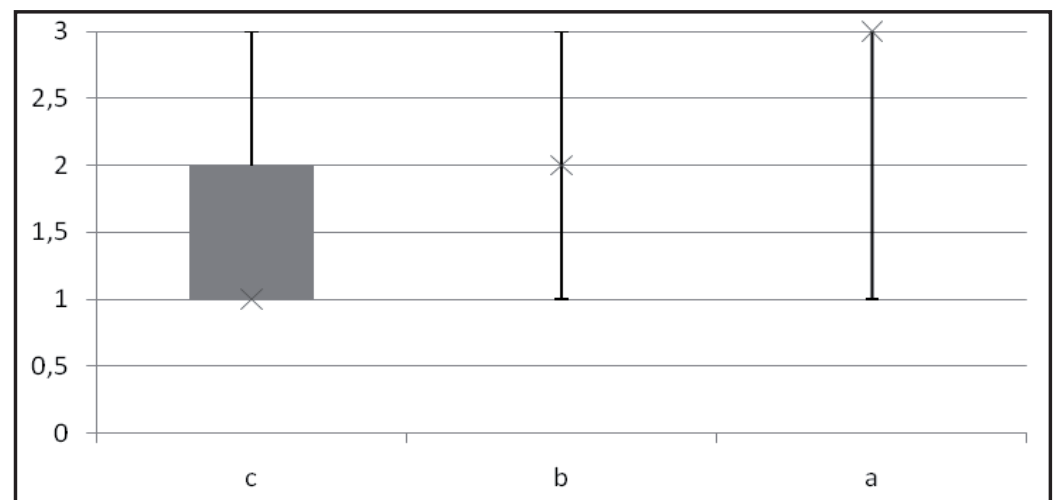


A partir de estos resultados, la jerarquización de los criterios es la siguiente:

1. c) No utilización de medios ilegales para obtener información de la competencia.

2. b) No difundir información falseada de los competidores.

3. a) Participación de la empresa en foros del sector.

\subsection{Administraciones Públicas}

En la tabla 1 presentamos la valoración efectuada por los expertos según la escala Likert. En este caso sólo tenemos dos criterios y las valoraciones hechas por los expertos son similares. Si las comparamos con los resultados estadísticos de la tabla 1 , puede verse que el $1^{\circ}$ es el criterio " $b$ ", ya que tiene una mediana de 1 , mientras que el criterio " $a$ " tiene una mediana de 2.

TABLA I2: Resultados de la valoración de los criterios. En \%

\begin{tabular}{|l|c|c|c|c|c|}
\hline \multicolumn{1}{|c|}{ Criterios } & $\begin{array}{c}\text { Muy de } \\
\text { acverdo }\end{array}$ & $\begin{array}{c}\text { De } \\
\text { acuerdo }\end{array}$ & Indiferente & $\begin{array}{c}\text { En } \\
\text { desacuerdo }\end{array}$ & $\begin{array}{c}\text { Muy en } \\
\text { desacuerdo }\end{array}$ \\
\hline $\begin{array}{l}\text { a) La empresa participa en grupos de } \\
\text { trabajo y foros de expertos. }\end{array}$ & 33,3 & 66,7 & 0,0 & 0,0 & 0,0 \\
\hline $\begin{array}{l}\text { b) Colaboración con iniciativas } \\
\text { institucionales. }\end{array}$ & 58,3 & 33,3 & 8,3 & 0,0 & 0,0 \\
\hline
\end{tabular}

\section{Conclusión}

Desde hace unos años, ha ido aumentando la necesidad de evaluar la RSC. Naturalmente, una evaluación puede ser cualitativa, pero cuando deseamos entrar en comparativas entre empresas, cuando los inversores que quieren ser responsables piden información cuantitativa, contrastable, acerca de la responsabilidad social de las empresas que operan en bolsa, se hace necesario entonces un sistema de evaluación cuantitativa. Por ello surgieron las agencias de evaluación de la RSC, en Europa y en Estados Unidos, que analizamos en dos estudios ya citados. Estas agencias han aportado el gran logro de adentrarse decididamente en la evaluación cuantitativa de la RSC, pero a su vez han topado con otro muro, el de la legitimi- 
dad moral de utilizar unos criterios opacos. Estas agencias realizan la evaluación asignando a cada stakeholder buen número de indicadores, pero suelen negarse a dar a conocer al mercado cuáles son. Esta opacidad ha hecho que una cierta sombra de incredulidad cubra estas agencias.

En este estudio hemos mostrado cómo la aplicación del método Delphi a la selección de criterios evaluadores de la RSC aporta resultados interesantes, además de ofrecer una propuesta concreta y transparente. De los resultados obtenidos, destacamos las siguientes conclusiones:

- En general, se percibe que los expertos dan mucha importancia a todo lo que tiene que ver directamente con las personas.

- Los expertos han validado los stakeholders propuestos, matizando que se debería incorporar el stakeholder "ONG".

- Los expertos han validado todos los criterios que hemos propuesto.

- Los criterios más relevantes en el stakeholder "clientes/consumidores" están relacionados con la fluidez de comunicación entre la empresa y los consumidores, con lo que se destaca que, en caso de reclamación, se responda siempre al consumidor, se facilite en el envasado el contacto con la empresa, se disponga de un responsable de atención al cliente, y se realicen valoraciones sobre la satisfacción del cliente.

- El criterio más destacable en el stakeholder "proveedores" consiste en que la empresa exija el cumplimiento de los derechos humanos a sus proveedores, mientras que el menos relevante es el hecho de que la empresa realice valoraciones de satisfacción del proveedor.

- En el stakeholder "empleados", lo que más valoran los expertos es que la empresa cuide a sus trabajadores velando por la igualdad de oportunidades, posibilitando la formación de los empleados y la existencia de normas escritas contra las prácticas discriminatorias entre los empleados, mientras que el menos relevante es el hecho de que los documentos internos de la empresa estén escritos en todas las lenguas donde la empresa tenga oficinas.

- El criterio más relevante en el stakeholder "sociedad" está relacionado con la responsabilidad de la empresa en sus acciones, con lo que se subraya la importancia de que ella realice un seguimiento de las repercusiones de sus 
actividades, mientras que el menos significativo es el hecho de que la empresa realice mecenazgo cultural.

- El criterio más relevante en el stakeholder "medio ambiente" vuelve a estar relacionado con la responsabilidad de la empresa en sus acciones, y se considera primordial que la empresa posea políticas de prevención de la contaminación.

- En el stakeholder "propietarios" destaca claramente la realización de auditorías periódicas de la gestión de la empresa.

- El criterio claramente más destacable en el stakeholder "alta dirección" es el hecho de que la empresa defina su misión y su código ético.

- La jerarquización de los criterios en los stakeholders "competencia" y "administraciones públicas" no es relevante.

Si bien, tal como se anunciaba en la introducción, se podría ampliar esta investigación con expertos de otros países, los resultados que se han obtenido, tanto en lo que a la validación de stakeholders y de criterios se refiere, como en la jerarquización de dichos criterios, pueden resultar de gran utilidad a aquellas empresas que deseen implantar o revisar sus políticas de RSC, puesto que partirán de unos resultados que son fruto de las reflexiones de personas y empresas dedicadas a la práctica de la RSC y del tratamiento riguroso de dichas reflexiones mediante el método Delphi.

\section{Bibliografía y páginas web}

AlCAMPO (2009), Informe de Responsabilidad Social Corporativa 2009, documento on line, <http://www.alcampo.es/WebPortal/Repository/Alcampo/Recursos/ AlcampoRSC2009.pdf>, consulta: julio 2010.

Badalona Serveis Assistencials: <http://www.bsa.cat/bsaweb/Home.do? terminternalCode=AGR55>, consulta: julio 2010.

Bejar, Y. (2009), "Publications d'informations sur le capital immatériel et attentes des investisseurs: une étude exploratoire par la méthode Delphi", Comptabilité Contrôle-Audit, tomo 15, vol. 2, pp. 165-192. 
Bon Preu (2007), Memòria de Sostenibilitat 2006/07, document on line, <http:// www.bonpreu.cat/admin/uploads/htmlarea/MEMORIA\%20BP\%20web\%202008. pdf?, consulta: julio 2010.

Camprodon, M., Sols, J., Florensa, A. (2006), "Las agencias de evaluación de la Responsabilidad Social Corporativa: estudio de un caso", Revista de Fomento Social, n. 244, vol. 61, pp. 393-422.

- (2009), "Las agencias estadounidenses de la evaluación de la Responsabilidad Social Empresarial", Revista de Fomento Social, n. 254, vol. 64, pp. 259-286.

CEEI Valencia - Fundación ÉTNOR (2004), Guía de responsabilidad social de la empresa, Valencia.

Coca Cola (2008), Informe de Sostenibilidad 2008, documento on line, <http:// www.conocecocacola.com/documentos/informe_sostenibilidad_08.pdf5, consulta: julio 2010.

Comisión de las Comunidades Europeas (2001), Libro Verde. Fomentar un marco europeo para la Responsabilidad Social de la Empresa, documento on line, <http://eur-lex.europa.eu/LexUriServ/LexUriServ.do?uri=COM:2001:0366:Fl $\mathrm{N}: \mathrm{ES}: \mathrm{PDF}>$, consulta: marzo y abril 2010.

Comisión de Responsabilidad Social Corporativa de AECA (2003), Marco conceptual de la responsabilidad social corporativa, Madrid.

CORTINA, A (2007), Ética de la razón cordial. Educar en la ciudadanía en el siglo $X X I$, Oviedo, Nobel.

- (1994), Ética de la empresa. Claves para una nueva cultura empresarial, Madrid, Trotta.

- (1986), Ética mínima. Introducción a la filosofía práctica. Madrid, Tecnos.

DKV (2009), Informe de Sostenibilidad 2009, documento on line, <http://cde. bluevista.es/1M4c445ac5cae9f348.cde>, consulta: julio 2010.

DALKey, N. - Helmer O. (1963), "An experimental application of the Delphi method to the use of experts", Management Science, vol. 9, pp. 458-467. 
DÉJEAN, F. (2005), L'investissement socialement responsable. Étude du cas français, París, Vuibert.

Esteve (2009), Memoria de Sostenibilidad 2009, documento on line, <http://www.esteve.es/EsteveFront/CargarPagina.do?pagina=est_memsos. isp\&div=par\&cm=145>, consulta: julio 2010.

FEIQUE (2008), "Guía de Responsabilidad Social Corporativa de la Industria Química", documento on line, <http://www.mityc.es>, consulta: marzo y abril 2010.

Ferrocarrils de la Generaltat de Catalunya: <hHtp://www.fgc.es/cat/responsabilitat_social.asp>, consulta: julio 2010.

Fontrodona, J. (2005), Gestión Integral de la RSE: el caso de Novartis en España, Col. Cuadernos Forética, n. 2, Madrid, Forética.

GRI (2006), "Guía para la elaboración de memorias de sostenibilidad", documento on line, <http://www. globalreporting.org/NR/rdonlyres/415F297B-5289 -4160-8B6C-7CC034D5BE52/0/G3_GuidelinesESP.pdf7, consulta: marzo y abril 2010.

IBERDROLA (2009), Informe de Sostenibilidad 2009, documento on line, <http:// www.iberdrola.es/webibd/gc/prod/es/doc/IA_InformeSostenibilidad09.pdf>, consulta: julio 2010.

KH LLOREDA (2006), Memoria Sostenibilidad 2006, documento on line, <http://www. khlloreda.com/idioma/es/pdf/KH_memoria_2006.pdf\$, consulta: julio 2010.

LA FAGEDA: <http://www.fageda.com>, consulta: julio 2010.

LANDETA, J. (1999), El método Delphi. Una técnica de previsión para la incertidumbre, Barcelona, Ariel.

Landeta, J. - Matey, J. - Ruiz, V. (2003), "Aplicación del método Delphi en la elaboración de la tabla simétrica de las Tablas Input-Output 2001 de Catalunya (TIOC-2001)", Instituto de Economía Aplicada a la Empresa de la Universidad del País Vasco, documento "on line", <http://www.idescat.cat>, consulta: enero 2010. 
MRW (2008), Memoria Social 2008, documento "on line", <http://www.mrw.es/ comuns/memoria/mem2008.pdf>, consulta: julio 2010.

NestĹ: <http://www.nestle.es/web/conoce_respons.asp>, consulta: julio 2010.

Nomenclatura de Actividades Económicas de la Comunidad Europea 2007, <http:// www.madrid.org>, consulta: febrero 2010.

The Timberland Company (2008), Corporate Social Responsibility Report 2007-08, document on line, <http://www.earthkeeper.com/Resource_/PageResource/20072008_Timberland_CSR_Report.pdf\$, consulta: julio 2010. 